\title{
Alcohol Use Disorder, Neurodegeneration, Alzheimer's and Parkinson's Disease: Interplay Between Oxidative Stress, Neuroimmune Response and Excitotoxicity
}

\section{OPEN ACCESS}

Edited by:

Małgorzata Kujawska,

Poznań University of Medical

Sciences, Poland

Reviewed by:

Kimberly Nixon,

University of Texas at Austin,

United States

Fabio Coppedè,

University of Pisa, Italy

*Correspondence:

Jaya Kumar

jayakumar@ukm.edu.my

Specialty section:

This article was submitted to

Cellular Neuropathology,

a section of the journal

Frontiers in Cellular Neuroscience

Received: 03 June 2020 Accepted: 10 August 2020 Published: 31 August 2020

Citation:

Kamal H, Tan GC, Ibrahim SF

Shaikh MF, Mohamed IN

Mohamed RMP, Hamid AA,

Ugusman A and Kumar J (2020)

Alcohol Use Disorder,

Neurodegeneration, Alzheimer's

and Parkinson's Disease: Interplay

Between Oxidative Stress,

Neuroimmune Response

and Excitotoxicity.

Front. Cell. Neurosci. 14:282.

doi: 10.3389/fncel.2020.00282

\begin{abstract}
Haziq Kamal', Geok Chin Tan², Siti Fatimah Ibrahim', Mohd. Farooq Shaikh', Isa Naina Mohamed ${ }^{4}$, Rashidi M. Pakri Mohamed5, Adila A. Hamid', Azizah Ugusman' and Jaya Kumar ${ }^{*}$

'Department of Physiology, Faculty of Medicine, Universiti Kebangsaan Malaysia, Kuala Lumpur, Malaysia, ${ }^{2}$ Department of Pathology, Faculty of Medicine, Universiti Kebangsaan Malaysia, Kuala Lumpur, Malaysia, ${ }^{3}$ Neuropharmacology Research Laboratory, Jeffrey Cheah School of Medicine and Health Sciences, Monash University Malaysia, Selangor, Malaysia, ${ }^{4}$ Department of Pharmacology, Faculty of Medicine, Universiti Kebangsaan Malaysia, Kuala Lumpur, Malaysia, ${ }^{5}$ Department of Family Medicine, Faculty of Medicine, Universiti Kebangsaan Malaysia, Kuala Lumpur, Malaysia
\end{abstract}

Alcohol use disorder (AUD) has been associated with neurodegenerative diseases such as Alzheimer's and Parkinson's disease. Prolonged excessive alcohol intake contributes to increased production of reactive oxygen species that triggers neuroimmune response and cellular apoptosis and necrosis via lipid peroxidation, mitochondrial, protein or DNA damage. Long term binge alcohol consumption also upregulates glutamate receptors, glucocorticoids and reduces reuptake of glutamate in the central nervous system, resulting in glutamate excitotoxicity, and eventually mitochondrial injury and cell death. In this review, we delineate the following principles in alcohol-induced neurodegeneration: (1) alcohol-induced oxidative stress, (2) neuroimmune response toward increased oxidants and lipopolysaccharide, (3) glutamate excitotoxicity and cell injury, and (4) interplay between oxidative stress, neuroimmune response and excitotoxicity leading to neurodegeneration and (5) potential chronic alcohol intake-induced development of neurodegenerative diseases, including Alzheimer's and Parkinson's disease.

Keywords: alcohol, neurodegeneration, excitotoxicity, neuroinflammation, neuroimmune, Alzheimer, Parkinson, oxidative

\section{INTRODUCTION}

According to the World Health Organization, 5.3\% of all global deaths and 5.1\% of the global burden of disease and injury are attributable to alcohol use disorder (AUD). Alcohol abuse increases the risks of both communicable and non-communicable diseases (World Health and Organization, 2019). Sudden cessation from heavy drinking results in manifestations of various physical symptoms, known as Alcohol Withdrawal Syndrome (AWS), and are primarily evident during the first 6-96 $\mathrm{h}$ following the last alcohol intake. AWS is often characterized by autonomic hyperactivity, agitation, hallucination and seizures (Mirijello et al., 2015; Jesse et al., 2017). Over the years, the majority of the alcohol-related 
studies focused on positive and negative reinforcement effects of the beverage (Salling et al., 2016; Mohamed et al., 2018a,b).

Alcohol-dependent individuals are prone to develop neurocognitive impairment and even neurodegenerative disorders (De la Monte and Kril, 2014). Findings from numerous investigations showed increased risk of neurodegenerative disorders such as dementia, and Parkinson's Disease with excessive alcohol consumption (Eriksson et al., 2013; Lafortune et al., 2014; Zhang D. et al., 2014; Heymann et al., 2016; Schwarzinger et al., 2018). In this review, we described alcoholinduced oxidative stress, heightened glutamatergic excitotoxity, exacerbated neuroimmune response, and their collective effects leading to neurodegeneration and potential association with certain neurodegenerative diseases, such as Alzheimer's disease and Parkinson's disease.

\section{AUD-INDUCED NEURODEGENERATION}

Chronic excessive alcohol intake often leads to cognitive impairment with white matter (WM) atrophy, axonal loss and demyelination at brain regions, including the hippocampus (Harper et al., 1985; De la Monte, 1988), frontal lobe (Harper and Matsumoto, 2005), and corpus callosum (Kapogiannis et al., 2012). Post-mortem analysis of rats' brains revealed a direct relationship between the degree of WM atrophy and the amount of alcohol consumed (Yalcin et al., 2017). Chronic binge alcohol consumption impairs normal WM lipid homeostasis, such as sulfatides and phospholipids, which are crucial for maintaining myelin integrity (Yalcin et al., 2017).

Findings from pre-clinical and clinical studies suggest interconnectivity between neuroimmune response, oxidative stress, and hyperglutamatergic excitotoxicity in mediating alcohol-induced neurodegeneration. Higher levels of bacterial endotoxin lipopolysaccharides (LPS) in alcoholics induce oxidative stress by increasing reactive oxygen species (ROS) production (Crews et al., 2015; Gorky and Schwaber, 2016). In response to this, neurons and glial cells (i.e., microglia, astrocytes, and oligodendrocytes) mediate neuroimmune reactions through interactions with neuroimmune factors such as Toll-like receptors (TLRs), high-mobility group protein box 1 (HMGB1), and pro-inflammatory cytokines. Oxidative stress is further exacerbated by glutamate excitotoxicity through upregulation of glutamate receptors upon chronic alcohol intake (Kumar et al., 2016), and also damage astrocytes, which are responsible for at least $90 \%$ of glutamate reuptake in rats (Ayers-Ringler et al., 2016).

\section{PATHOPHYSIOLOGY OF AUD-INDUCED NEURODEGENERATION}

\section{Alcohol-Induced Oxidative Stress in Brain}

Oxidative stress is fundamental to the etiology of many diseases (Kumar et al., 2017; Liguori et al., 2018). In AUD, alcohol utilizes oxidative stress as one of the main tools to wreak havoc in central nervous system. Primarily, alcohol is metabolized by alcohol dehydrogenase (ADH) and Cytochrome P450 (CYP450) in the liver. The brain is devoid of ADH (Roberts et al., 1995), hence alcohol metabolism in brain is predominantly facilitated by CYP450 subtype 2E1 (CYP2E1) (García-Suástegui et al., 2017). CYP2E1 is localized in various cellular sites, including the plasma membrane, endoplasmic reticulum (ER), Golgi apparatus and highly expressed in the mitochondria. By-products of alcohol metabolism by CYP2E1 are acetaldehyde and reactive oxygen species (ROS), like radical superoxide anion $\left(\mathrm{O}_{2}^{-}\right)$and hydrogen peroxide $\left(\mathrm{H}_{2} \mathrm{O}_{2}\right)$ (García-Suástegui et al., 2017).

Reactive oxygen species induce oxidative stress in cells and potentially damage the neurons. Endogenous antioxidants such as superoxide dismutase (SOD), glutathione peroxidase (GPX), and reduced glutathione (GSH) are important for ROS elimination. SOD inactivates radical $\mathrm{O}_{2}^{-}$and forms $\mathrm{H}_{2} \mathrm{O}_{2}$. In the GPX reaction, GSH serves as an electron donor for $\mathrm{H}_{2} \mathrm{O}_{2}$ that subsequently removes ROS (Kim et al., 2015). Acute and chronic alcohol consumption decreased GSH level in the brain (Guerri and Grisolia, 1980). Prolonged oxidative stress in the brain causes neuronal dysfunction and cell death, which could lead to neurodegeneration (Bhat et al., 2015).

Aside from CYP2E1, lipopolysaccharides (LPS), a serum bacterial endotoxin also was associated with alcohol consumption and oxidative stress. A previous study reported significantly high plasma LPS concentration in alcoholics who just enrolled in a detoxification program compared to control and recovering alcoholics post-2 weeks of abstinence (Leclercq et al., 2012). LPSinduced oxidative stress promotes ROS production by activating nicotinamide adenine dinucleotide phosphate (NADH) oxidase (NOX). An in vivo study reported an increase in NOX expression following systemic LPS administration $(5 \mathrm{mg} / \mathrm{kg})$ in mice. The LPS-induced ROS expression remained high even 20 months after the last LPS injection (Qin et al., 2013). A single high dose of LPS (5 mg/kg), given intraperitoneally (ip) shows persistent microglial activation and release of proinflammatory mediators, such as tumor necrosis factor $\alpha(\mathrm{TNF} \alpha)$, monocyte chemoattractant protein-1 (MCP-1), and interleukin-1 beta (IL$1 \beta$ ) in the mouse brain (Qin et al., 2013; Figure 1).

\section{Alcohol-Oxidative Stress-Induced Mitochondrial Apoptosis}

Oxidative stress refers to an imbalance of the redox system characterized by excessive level of free radicals and impaired antioxidant system. Prolonged alcohol drinking worsens oxidative stress affecting the whole cell, or specific cellular constituents including proteins, lipids, and DNA (Hernández et al., 2016). The brain is one of the most metabolically active organs and thus, it is profoundly susceptible to oxidative stress, owing to its high demand for oxygen consumption and low levels of endogenous antioxidants to eliminate free radicals (Kim et al., 2015). Mitochondria are the major energy factory, providing at least $90 \%$ of cellular adenosine triphosphate (ATP) (Salin et al., 2015). Furthermore, the brain is abundant with phospholipids that contain a high amount of polyunsaturated fatty acids (PUFA) and therefore, is susceptible to lipid peroxidation (LPO) 


\section{Peripheral}

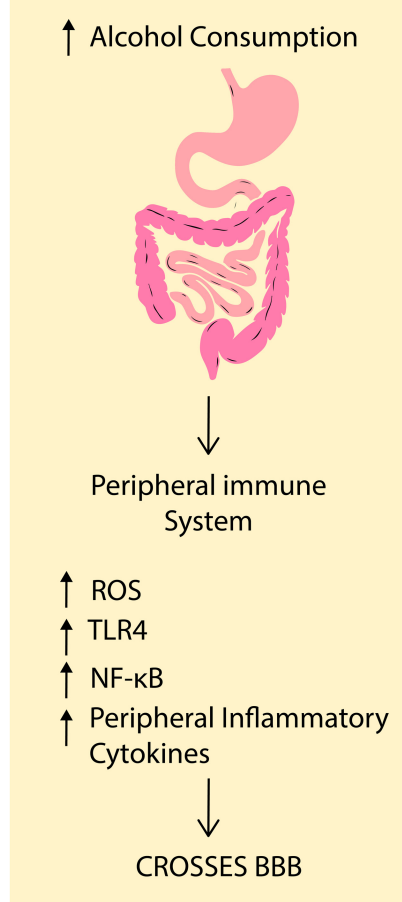

Central

Neuroinflammation Induced-Cell Death

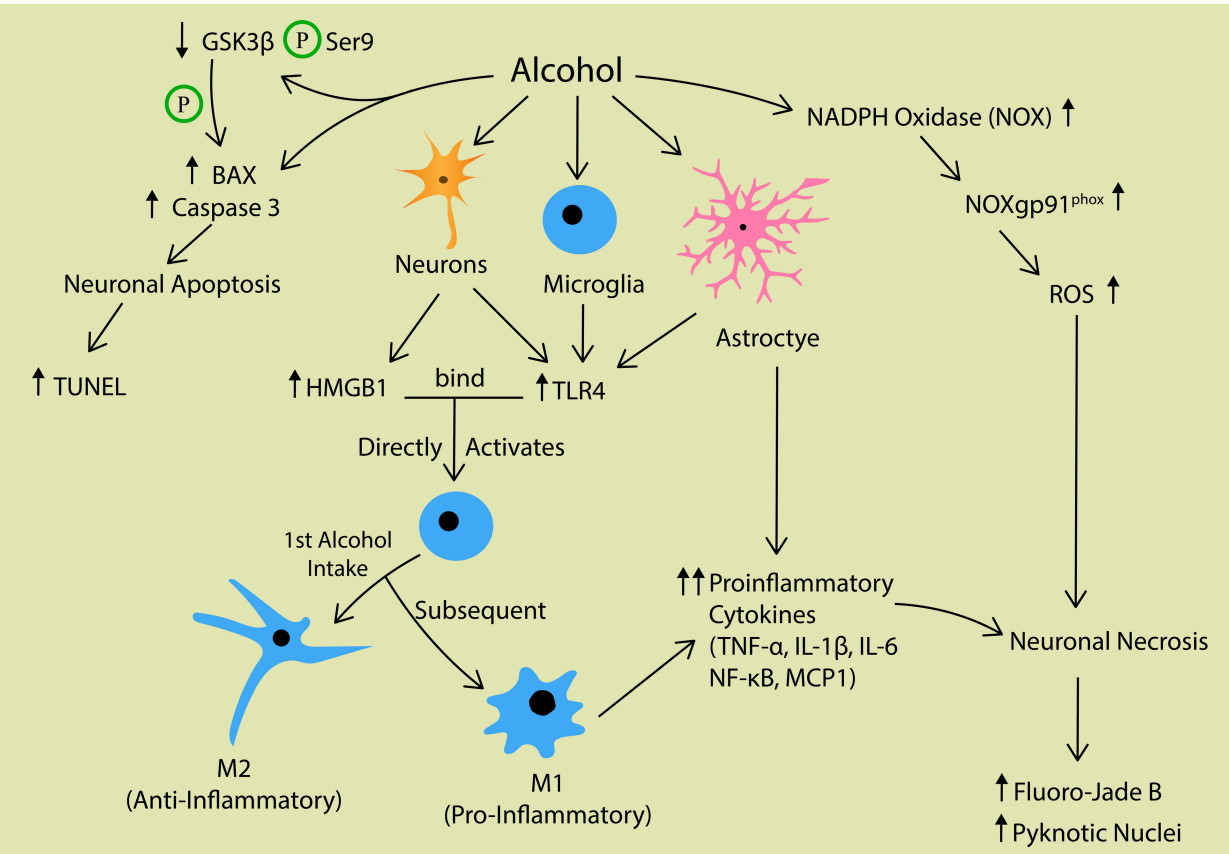

(P) Phosphorylation

FIGURE 1 | The crosstalk between peripheral and central immune system in Alcohol Use Disorder (AUD) leading to cell death. Alcohol consumption increases the peripheral production of reactive oxygen species (ROS), Toll-like receptor 4 (TLR4), nuclear factor kappa-light-chain enhancer of activated B cells (NF-кB) and inflammatory cytokines, which cross the blood brain barrier (BBB). At central nervous system, alcohol induces neuroinflammation that potentially leads to apoptosis or neurosis. Alcohol stimulates more B-cell lymphoma-2-associated X (BAX) formation, Caspase 3 expression and activates Glycogen synthase kinase-3 $\beta$ (GSK3 $\beta$ ) by reducing its Serine 9 phosphorylation. GSK3 $\beta$ also directly phosphorylates BAX leading to neuronal apoptosis. Alcohol stimulates neuronal release of HMGB1 and TLR4 expression on microglia, astrocytes and neurons. HMGB1-TLR4 interaction activates microglia into; M1 phenotye (anti-inflammatory) during 1st alcohol intake, and M2 phenotype (pro-inflammatory) in subsequent alcohol exposure. M2 phenotype and astrocytes releases several pro-inflammatory cytokines including tumor necrosis factor-alpha (TNF- $\alpha$ ), interleukin 1 Beta (IL-1 $\beta$ ), interleukin-6 (IL-6), NF-кB and monocyte chemoattractant protein-1 (MCP1). Alcohol stimulates ROS production by increasing NADPH-dependent oxidase (NOX), NOXgp91 ${ }^{\text {phox }}$ expression and activity, leading to oxidative stress. Collectively alcohol-induced neuroinflammation and oxidative stress causes neuronal death via apoptosis and necrosis pathways.

(Kim et al., 2015). Besides LPO, alcohol-induced oxidative stress also causes protein and DNA damage, mitochondrial dysfunction, increased cytokine production and eventually neuronal cell death (García-Suástegui et al., 2017).

As the "powerhouse" of the cell (Salin et al., 2015), mitochondria are also the main source of ROS production (Kim et al., 2015). Oxidative stress by mitochondrial dysfunction and damage is widely accepted as one of the mechanisms that orchestrate neurodegeneration (Fischer and Maier, 2015; Figure 2). Cardiolipin (CL), a mitochondrial-specific phospholipid is believed to play a major role in the development of AUD-induced neurodegeneration. CL was found almost entirely in the inner mitochondrial membrane and necessary for maintaining normal mitochondrial functions (Xiao et al., 2017). Adult rats exposed to alcohol (20\% ethanol via oral gavage for 60 days) showed significant changes in nitric oxide
(NO), SOD2 and CL levels in mitochondria extracted from the brain cortex. Findings from the study revealed the nitric oxide (NO) levels to be significantly increased, while SOD2 expression reduced denoting alcohol-induced oxidative stress. Bilayer chromatography showed at least $40 \%$ decrease in $\mathrm{CL}$ level. The authors also reported decreased membranebound $\mathrm{Na}^{+} / \mathrm{K}^{+}$-ATPase activity suggestive of suppressed cell respiratory function. The decreased mitochondrial complex I, III, and IV activity led to mitochondrial dysfunction (Reddy et al., 2013). In the event of mitochondrial dysfunction, partial membrane potential reduction in mitochondria signals for non-oxidized CL translocation from the inner mitochondrial membrane, to the mitochondrial outer membrane (MOM) (Kagan et al., 2015). CL translocation, in return, activates B-cell lymphoma-2-associated X (BAX), which promotes cell apoptosis (Kim-Campbell et al., 2019). 


\section{Excitotoxicity induced-Cell Death}

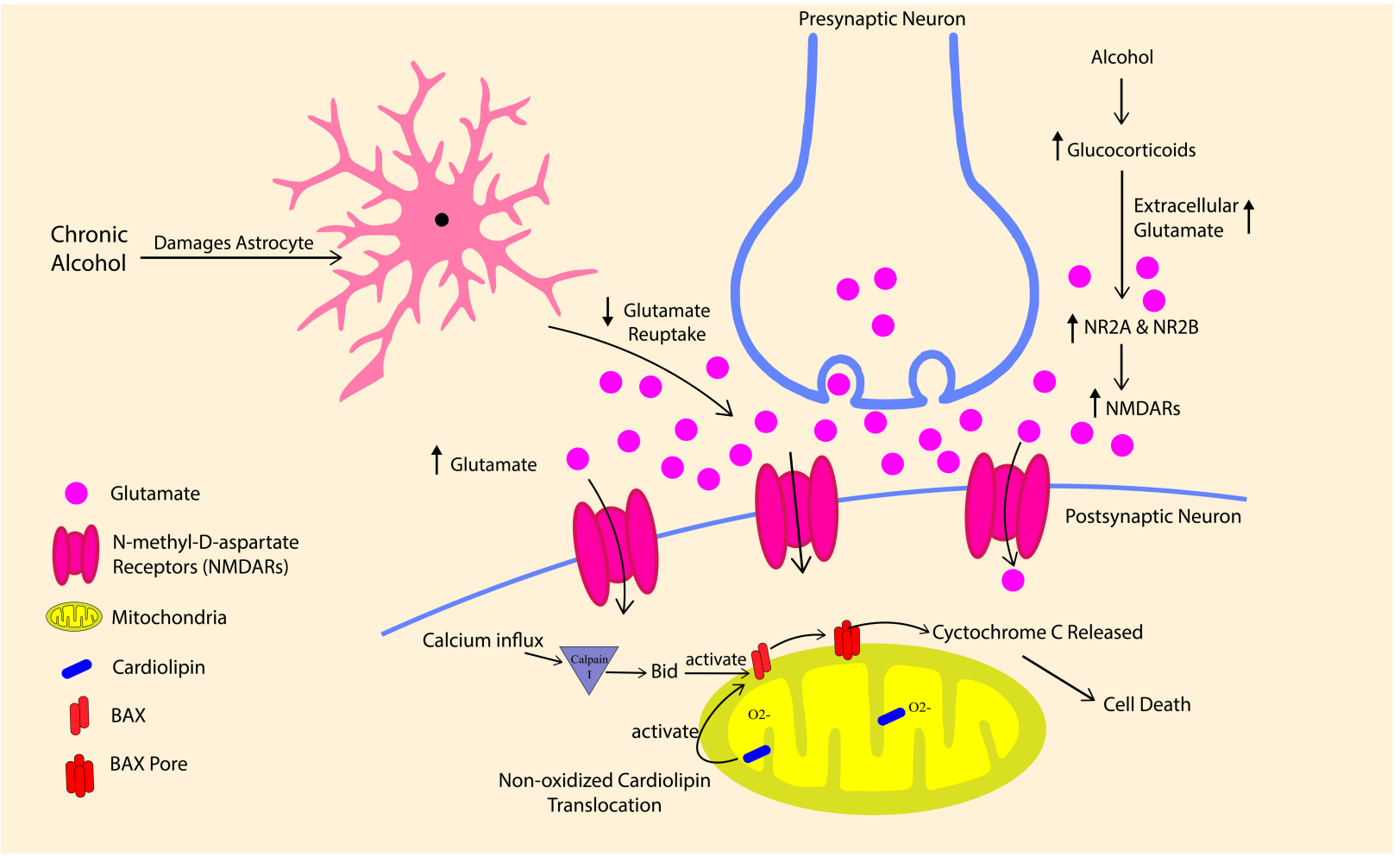

FIGURE 2 | Alcohol-excitotoxicity induced cell death through glutamate and glucocorticoids. Chronic alcohol consumption damages astrocyte and its ability to regulate extracellular glutamate concentration, leading to hyperglutamatergic excitotoxicity. Chronic alcohol consumption increases glucocorticoids level, further elevating extracellular glutamate concentration. Alcohol-induced glucocorticoids also worsen alcohol-excitotoxicity induced cell death by increasing

N-Methyl-D-aspartate receptors (NMDARs) and its subunit expression, NR2A and NR2B. NMDARs overactivation causes calcium influx and causes cardiolipin translocation, leading to B-cell lymphoma-2-associated $X(B A X)$ pore formation on mitochondria, which releases cytochrome c causing neuronal cell death.

\section{Stress-Induced Neuroimmune Response Signaling}

Alcohol-induced oxidative stress initiates the innate immune response as a countermeasure by promoting the cross-talk between neurons and glial cells (i.e., microglia, and astrocytes). Prior to cell necrosis or apoptosis, affected cells release an endogenous signal namely, Danger-associated-molecular patterns (DAMPs) alarming the innate immune system for cellular damage and potential cell death (Frank et al., 2015). Chronic alcohol intake was reported to induce the neuronal release of High-mobility group box 1 (HMGB1), an endogenous DAMP (Zou and Crews, 2014). Furthermore, alcohol-induced exogenous pathogen-associated molecular patterns (PAMPs) such as LPS also trigger the innate immune system (Frank et al., 2015). In rat hippocampal-enthorhinal cortex (HEC), HDAC regulates the neuronal release of acetylated HMGB1 in response to alcohol exposure (Zou and Crews, 2014). As pattern recognition receptors, TLRs are responsible for an innate response to cellular injury and exposure to pathogens. Among various TLRs, activation of TLR4 promotes neuroimmune response and their expression on neurons, microglia, and astrocytes (Coleman and Crews, 2018). HMGB1 and LPS are ligands of TLR4 and thus stimulates the receptor, and recent studies have linked alcohol exposure and their expression on neurons. Rats' HEC slices treated with alcohol and HMGB1 increases expression of TLR4 and inflammatory mediators such as tumor necrosis factor-alpha (TNF- $\alpha$ ), interleukin 1 Beta (IL$1 \beta)$, nuclear factor kappa-light-chain enhancer of activated B cells (NF- $\mathrm{B}$ ) and monocyte chemoattractant protein-1 (MCP1) (Zou and Crews, 2014), suggesting a functional link between HMGB1TLR4 and alcohol-induced neuroinflammation in brain. Due to large molecular size, LPS is impermeable to blood-brain barrier $(\mathrm{BBB})$ and therefore, thought to affect the brain via peripheral immune system (Mayfield et al., 2013; Frank et al., 2015). LPS binding to peripheral TLR4, triggers a neuroimmune response within the brain by increasing NF- $\kappa$ B expression and subsequent peripheral inflammatory cytokine release to cross BBB (Mayfield et al., 2013; Coleman and Crews, 2018). These findings corroborate the association between LPS and peripheral immune-to-brain signaling pathways.

HMGB1 and LPS also directly activate microglia via TLR4 recognition (Frank et al., 2015). In response to inflammatory stimuli, microglia are activated into two main phenotypes; (1) 
M1 or classical activation exists in an amoeboid shape and secretes pro-inflammatory factors; (2) M2 or alternate activation exists as a ramified projection and secretes anti-inflammatory factors. Activated microglia exacerbates neuroinflammatory response and promotes cell death via caspase cascade by releasing more pro-inflammatory cytokines such as TNF- $\alpha$, and free radicals, suggesting a role for microglia in AUDinduced neurodegeneration (Coleman and Crews, 2018). Most studies investigating the effects of alcohol exposure on microglia activation have reported both M1 and M2 phenotypes (Ward et al., 2009; Marshall et al., 2013, 2016; Peng et al., 2017). Expression of microglia phenotypes depends on type of AUD models employed. Intermittent exposure model has reported the pro-inflammatory phenotypes, whereas the continuous intoxication model reported anti-inflammatory phenotypes (Ward et al., 2009; Marshall et al., 2016; Figure 1). A shift in microglial phenotypes was also proposed between first and subsequent binge exposure to alcohol, where first exposure results in low-grade microglial activation resembling M2 phenotype, and subsequent exposure generates more pro-inflammatorylike events such as increase in OX-42 immunoreactivity, ionized calcium-binding adapter molecule 1 (Iba-1+) cells, and TNF- $\alpha$ (Marshall et al., 2016). The findings suggest a more dynamic activation of microglia over time in alcohol dependent individuals with episodic binge drinking pattern. Ethanol-induced alterations in brain cytokines are also mediated by cells other than microglia, since acute minocycline injection (inhibitor of microglia) did not completely reversed ethanolinduced cytokine changes in the brain (Doremus-Fitzwater et al., 2014). In line with this finding, depletion of microglia (through administration of colony stimulating factor 1 (CSF1R) inhibitor, PLX5622) decreased expression of some neuroimmune genes (TNF-a), but not most of them (IL-1B, IL-6, Ccl2 etc.). Depletion of microglia also significantly reduced TLR2 and TLR7, but not TLR3 or TLR4 (Walter and Crews, 2017), which was thought to be mainly expressed in microglia. Apart from microglia, numerous other cells in the CNS also produce cytokines and express cytokine receptors. Inteleukin-6 (IL-6), the most consistently associated cytokine to ethanol exposure (DoremusFitzwater et al., 2014, 2015) is produced by numerous types of brain cells such as neurons (Schöbitz et al., 1993; Ringheim et al., 1995), astrocytes (Benveniste et al., 1990), and endothelial cells (Reyes et al., 1999). TLRs that are prominently expressed on microglia such as TLR3 and TLR4 are also expressed in other cell types, including neurons (Vetreno and Crews, 2012; June et al., 2015), astrocytes, and endothelial cells (Zhang Y. et al., 2014). It is also likely that changes in secretion of cytokines depend on time (acute, intoxication, withdrawal), brain region, and blood alcohol levels. For example, TNF- $\alpha$ and IL-1 are significantly increased during abstinence, however, unchanged or reduced during intoxication. IL-6 was significantly expressed during intoxication, but not withdrawal. Increased expression of IL-6 during ethanol withdrawal was witnessed only in hippocampus, not in hypothalamus or cerebellum (Doremus-Fitzwater et al., 2014). Among the aforementioned cytokines, some promote proinflammatory response (IL-1 $\beta$, TNF- $\alpha$, IL-6, Ccl2) whereas some mediate anti-inflammatory reaction (IL-10, IL-4, IL-1ra, TGF- $\beta$ ).
Therefore, it appears that CNS is placed in a continuum between pro- and anti-inflammatory events, depending on the type of cells, regions, cytokines released and stages of AUD orchestrating the neuroimmune response.

\section{Alcohol-Induced Hyperglutamatergic Excitotoxicity}

Alcohol affects the neuronal structures and functions by directly passing through the BBB (Cornford et al., 1982; Szabo and Lippai, 2014). Alcohol alters the inhibitory actions of $\gamma$-Aminobutyric acid (GABA), and excitatory glutamatergic innervations (Kumar et al., 2013, 2016, 2018). Acute alcohol consumption suppresses and chronic intake upregulates the expression of glutamate receptors (Chandrasekar, 2013), eventually exposing neurons to injury via N-Methyl-D-aspartate receptors (NMDARs)associated excitotoxicity (Fricker et al., 2018). Alcohol also increases extracellular glutamate concentration by limiting glutamate reuptake by glutamate transporter-1 (GLT-1). GLT-1 is accountable for at least $90 \%$ extracellular glutamate clearance (Rao et al., 2015). Post-mortem analysis of alcoholic brains shows a decreased expression of GLT-1 in the basolateral amygdala region compared to non-alcoholic brains (Kryger and Wilce, 2010). Failure to regulate glutamate intake also was implicated in neurological diseases such as Alzheimer's disease (Maragakis and Rothstein, 2006). Overactivation of NMDARs results in a surge of $\mathrm{Ca}^{2+}$ influx into neurons and stimulates mitochondrial injury and death. In line with this, hippocampal slices exposed to chronic intermittent alcohol and $24 \mathrm{~h}$ withdrawal significantly reduced the mature neuron marker, known as Neuron-specific nuclear protein (NeuN), and nissle bodies compared to continuous alcohol exposure, demonstrating a more profound detrimental effects of excitotoxicity during the withdrawal period (Reynolds et al., 2015). Elevated intracellular $\mathrm{Ca}^{2+}$ activates Calpain I, a highly expressed protease in neurons. In brain, chronic alcohol intake increases calpain activity in rats' cerebral cortex and cerebellum (Rajgopal and Vemuri, 2002), and hippocampus Dwivedi et al. (2018). Furthermore, administration of calpain inhibitor A-705253 reduced alcoholseeking and relapse in chronic alcohol-fed rats (Vengeliene et al., 2016), suggesting the important role of caplain, not only in alcohol-induced cellular damage, but also in behavioral changes. Activated Calpain I, cleaves BH3-interacting domain death agonist (Bid) causing its activation and forming BAX pores on the mitochondrial membrane, which releases cytochrome $\mathrm{C}$ to cytosol and initiates apoptotic cell death via caspase cascade (Fricker et al., 2018; Figure 2).

The role of glucocorticoids (GCs) in alcohol-induced neuronal excitability and neurotoxicity also been well documented in past studies (Mulholland et al., 2005; Jacquot et al., 2008; For review, Prendergast and Mulholland, 2012). Alcohol consumption disrupts the function of hypothalamo-pituitary-adrenal (HPA) axis, which is shown through elevated blood GCs level in both humans and rodents (Errico et al., 2002; Lee et al., 2004). Circulating GCs significantly increased during ethanol withdrawal, however, little changes or mixed results were reported following chronic alcohol intake (Tabakoff et al., 1978; 
Adinoff et al., 2003; Little et al., 2008). In the brain, regional differences in GC level has been reported, most prominent changes noted during abstinence in hippocampus, prefrontal cortex, and thalamus across genders, and strains of rodents (Little et al., 2008). Prolonged increase in GCs was related to neuronal toxicity within the brain (Sapolsky, 2000; Erickson et al., 2003). GCs are known regulator of immune response (Sorrells and Sapolsky, 2007), was shown to reduce hippocampal dendritic complexity (Conrad et al., 2007) and cell death (MacPherson et al., 2005). GCs may cause neurotoxicity directly or indirectly via NMDARs. Chronic exposure to GCs elevates the protein expression of nucleotide-binding oligomerization domain-like receptor pyrin domain-containing 1 (NLRP-1), Caspase-1, Caspase-5, apoptosis associated speck-like protein (ASC), nuclear factor-jB (NF-jB), p-NF-jB, interleukin-1b (IL-1b), IL-18, IL-6, and microtubule associated protein 2 (MAP2) in the frontal cortex and hippocampus of male mice, suggesting GCs/NLRP1 inflammasome-mediated neurodegeneration (Hu et al., 2016). In a separate study, GCs-mediated neurotoxicity was reported in female, but not male mice. The authors reported upregulation in GCs target genes in medial prefrontal cortex of female mice during withdrawal from chronic ethanol exposure including astrocytic genes (Wilhelm et al., 2015). Exposure to GCs increases the concentration of extracellular glutamate (Abraham et al., 2001), and expression of NMDARs subunit levels NR2A and NR2B (Weiland et al., 1997). In organotypic hippocampal slice cultures, ethanol withdrawal alone had little effects on the propidium iodide fluorescence and in cytosolic $\mathrm{Ca}^{2+}$ accumulation (cytotoxicity), however, exposure to corticosterone resulted in cytotoxicity regardless of the exposure period. When exposed to ethanol, or ethanol withdrawal, the cytotoxic effect of corticosterone was the greatest, suggesting the potential role of ethanol in increasing the vulnerability to corticosterone-induced toxicity. Furthermore, these effects were inhibited by RU486 (antagonist of GCs) and MK-801 (non-competitive antagonist of NMDAR), indicating the role of NMDARs in corticosteroneinduced neurotoxicity in the presence of ethanol or ethanol withdrawal (Mulholland et al., 2005).

According to Collins and Neafsey (2016), alcohol-induced glutamate excitotoxicity has only been established in slice culture studies. Many investigators have attempted to understand hyperglutamatergic neurotransmission in AUD by measuring the level of glutamate or its metabolite levels, or glutamate receptor levels in human brain. Generally, brain glutamate level was reported to be low during active drinking (Ende et al., 2013; Prisciandaro et al., 2016), high during acute abstinence period (48-72 h into last alcohol intake) (Hermann et al., 2012), and abnormally low a week following the last alcohol intake (Mon et al., 2012). On the other hand, expression of glutamate receptors was found to be downregulated (Jin et al., 2014) and moderately increased (Freund and Anderson, 1996) in deceased alcoholic patients, and increased during 25 days of abstinence (Akkus et al., 2018). The closest finding to alcohol-induced neurotoxicity came from Frischknecht et al. (2017), associated significant increase in brain glutamate markers with lower gray matter hippocampal volume in both humans and rodents during abstinence. The authors associated high glutamine with reduced hippocampal volume 2 weeks after the abstinence, not during the early withdrawal phase, suggesting that neural damage could be a consequence of withdrawal, rather than intoxication. This finding is in agreement with a previous report that correlated alcohol withdrawal severity with reduced hippocampal volume during abstinence (Barnes et al., 2010). Some studies reported that brain glutamate levels normalize within longer periods of abstinence (Hermann et al., 2012; Mon et al., 2012), corresponding with improvement in brain gray and white matter volume during long-term sobriety (Pfefferbaum et al., 1995; O’Neill et al., 2001). Nevertheless, the direct link between alcohol-induced hyperglutamatergic state and excitotoxicity is yet to be proven in humans, and alcohol could negatively affect neuronal integrity through other mechanisms such as neuroinflammation and mitochondrial damage.

\section{Alcohol-Induced Neuronal Apoptosis}

Many studies have reported significant brain shrinkage, loss of hippocampal volume (Sullivan et al., 1995; Chen et al., 2012; Ozsoy et al., 2013), and white matter atrophy in alcoholdependent patients (De la Monte, 1988). Glycogen synthase kinase-3 $\beta$ (GSK3 $\beta)$, a serine/threonine kinase is integral in regulation of neuronal survival and neurogenesis (Luo, $2009,2010)$ and also a mediator of alcohol-induced neuronal apoptosis in the developing brain (Luo, 2012). Overexpression of GSK3 $\beta$ causes neuronal apoptosis in mice hippocampus with hyperphosphorylated Tau (Lucas et al., 2001). GSK3 $\beta$ activity is inhibited by its phosphorylation at Serine 9 (Ser9), and activated by phosphorylation at Tyrosine 216 (Tyr216) (Grimes and Jope, 2001). A recent in vivo study showed GSK3 $\beta$ mediates alcohol-induced hippocampal neurodegeneration (Ji et al., 2018). In this study, control rats expressed higher phosphorylated Ser9, whereas binge alcohol-treated rats showed dramatic reduction in Ser9 phosphorylation of GSK3 $\beta$ along significant decrease in number of mature neurons (NeuN) and newly formed neurons (doublecortin-positive cells) in hippocampus (Ji et al., 2018). Caspase 3 and BAX (proapoptotic proteins) are linked to alcohol-induced neurodegeneration via GSK3 $\beta$. Alcohol exposure increases the expression Caspase 3 and active BAX in cerebral cortex, whereas treatment with lithium, a GSK3 $\beta$ inhibitor reduced both alcohol-driven Caspase 3 and Bax upregulation (Liu et al., 2009). GSK3 $\beta$ directly phosphorylates Bax and promotes its apoptotic action (Linseman et al., 2004). Moreover, BAX is also a known downstream target of alcoholinduced GSK3 $\beta$-mediated neurodegeneration (Liu et al., 2009).

In addition to alcohol-induced apoptotic cell death, other forms of cell death such as necrosis (Obernier et al., 2002; Morris et al., 2010; Maynard et al., 2018) and even necroptosis (non-neuronal cells) (Afonso et al., 2015; Lu et al., 2016) been reported. Obernier et al. (2002) reported significant increase in markers of Fluoro-Jade B (FJB) and pyknotic nuclei (markers of cell necrosis) in all regions of corticolimbic circuit. Necrotic neurons were still apparent even two, three, and four days after the last alcohol treatment, whereas no signs of TUNEL positive cells (marker of apoptosis) were reported at any time points. Similar to these findings, Maynard et al. (2018) also reported significant increase in markers of FJB in binged male and female 
hippocampi, but not TUNEL, eight hours after the last intake of alcohol. Kelso et al. (2011) also reported significant increase in FJB markers in CA3 and dentate gyrus of hippocampus at two, four, and seven days after the last binge alcohol intake, and expression of FJB retuned to baseline only 14 days post binge intake. Apart from these findings, Morris et al. (2010), reported both FJB and TUNEL markers in the rodent hippocampus collected immediately after the last alcohol intake. However, the number of FJB, and pyknotic markers were higher than TUNEL, hence the authors concluded that binge-alcohol induced cell death is most likely due to necrosis, not apoptosis. In line with these findings, chronic alcohol was shown to increase microglial and astrocytes' activation, proinflammatory cytokines (TNFa, IL-1b, IL-6) and chemokines (MCP-1), and expression of a NADPH-dependent oxidase (NOX), resulting in generation of ROS. Subsequently, activation of NF- $k \beta$-mediated transcription exacerbates proinflammatory factors, further accentuating NOXROS (NOX-gp91 ${ }^{\text {phox }}$ ) and NF-k $\beta$ signaling cascade, causing cell death (activated caspase-3 and FJB as markers). Administration of diphenyleneidonium (DPI; NOX inhibitor) reduced caspase-3 immunoreactivity, and FJB expression, indicating the important role of NOX-FOS in alcohol-mediated cell death (Qin et al., 2008; Qin and Crews, 2012). Based on existing literature, both apoptosis and necrosis were reported during acute, chronic binge alcohol exposure, and withdrawal across various age, and strains of rodents. Some studies reported mediators in cell death pathways (such as apoptosis), however, the ratio to necrosis or apoptosis induced cell death were not reported. Therefore, it is still unclear whether the alcohol-induced cell death is driven by necrosis or apoptosis pathway. However, considering the time, gender, and regional differences in alcoholinduced cellular pathways, the possibility of a spectrum between necrosis and apoptosis in alcohol-induced neurotoxicity should be further explored.

\section{AUD-INDUCED NEURODEGENERATIVE DISEASE}

Motor impairments and lapses in memory are seen during intoxication and some cases of abstinence due to alcoholinduced neurological deficits (Lafortune et al., 2014). Longterm excessive intake of alcohol also attributes to more morbid neurological conditions such as Alzheimer's disease (AD) and Parkinson's disease (PD). Based on a Swedish National Cohort Study (1978-2008), out of 276,527 patients diagnosed with AUD and followed up for 37 years, 1,083 (0.4\%) were admitted with Parkinson's Disease (Eriksson et al., 2013). In another cohort study, conducted between 2008 and 2013 in France, AUD was the strongest modifiable risk factor for the dementia onset, encompassing $38.9 \%$ of 57353 diagnosed with early-onset dementia (Schwarzinger et al., 2018).

\section{Dementia or Alzheimer's Like Phenotypes}

Alzheimer's disease is mainly a collection of proteostasis disruption, namely; Tau tangles and Amyloid- $\beta$ (a $\beta)$. The formation of neurofibrillary tangles results from the aggregation of hyperphosphorylated tau protein (Boland et al., 2018). On the other hand, $a$ is generated through cleavage of amyloid precursor protein (APP) by beta-secretase (BACE1) (Huang et al., 2018). In humans, studies associating alcohol consumption and development of $\mathrm{AD}$ have yielded mixed results. Some have associated alcohol consumption with increased risk of AD (Fratiglioni et al., 1993; Harwood et al., 1999, 2010) (For review, Piazza-Gardner et al., 2013; Huang et al., 2016; Venkataraman et al., 2017) and faster rate of cognitive decline in AD patients (Heymann et al., 2016). Some found no association between alcohol consumption and AD (Tyas et al., 2000; Ruitenberg et al., 2002; Luchsinger et al., 2004), whereas some even reported alcohol consumption as a protective factor against AD (García et al., 2010; Weyerer et al., 2011; Kim et al., 2020). At present, association between AD and AUD, is only established at pre-clinical level. Adult male Sprague Dawley rats administered with intragastric alcohol $(4 \mathrm{mg} / \mathrm{ml})$ for 30 days recorded spatial reference memory and memory consolidation deficits along decrease in activities of PP2A, SOD, and increase in activity of GSK3 $\beta$ (hyperphosphorylates Tau), and levels of MDA, and hyperphosphorylated tau (Ser 199, Ser 396, Ser 404) in both hippocampus and cortex (Fang, 2017). Cyclin-dependent kinase $5(\mathrm{Cdk} 5)$, another kinase involved in hyperphosphorylation of Tau was reported to be upregulated upon chronic alcohol exposure (Rajgopal and Vemuri, 2001), in a region-specific manner (Camp et al., 2006). Alcoholinduced increase in $\mathrm{Cdk} 5$ may due to downregulation of its regulators p35 or p67 (Rajgopal and Vemuri, 2001), increase in calpain activities (Rajgopal and Vemuri, 2002), which stimulates p25 (activator of Cdk5) (Kusakawa et al., 2000). Parallel to these findings, another study reported increase in BACE1 and APP expression in rats' hippocampus following five weeks of alcohol liquid diet. Findings from the study suggest that alcohol enhances oxidative stress-induced BACE1 activity, and thus AD pathogenesis. Western blot analysis showed increased expression of proteins involved in BACE1 oxidative regulation such as presenilin (PS1) and nicastrin (Kim et al., 2011). Adult 3xTgAD mice (humanized mice that express human MAPT, APP, and PSEN-1 transgenes and manifest AD-like pathologies) given two-bottle home-cage alcohol/saccharin $(25 \% \mathrm{w} / \mathrm{v}+$ saccharin $0.1 \%, \mathrm{w} / \mathrm{v}$ ) for four months showed impaired spatial memory, exacerbated conditioned fear, and diminished sensory gating in a chronic non-dependent drinking model. Laboratory findings revealed an increase in $A \beta 42 / 40$ ratio in lateral entorhinal and prefrontal cortex, total Tau expression in medial prefrontal cortex, lateral entorhinal cortex, amygdala, and phosphorylated tau expression (Ser 199/Ser 202) in hippocampus. The ADlike pathologies also associated with reduced phosphorylation of phosphoproteins associated with Akt/mTOR signaling pathway in a brain region-specific manner [amygdala: ERK 1/2 (Thr 185/Tyr 187); Lateral hippocampus: IRS1 (Ser 636), p7056K (Thr 389/412); CA1: mTOR (Ser 2448), PTEN (Ser 380); lateral entorhinal cortex: IGF1R (Tyr 1135/1736), IR (Tyr 1162/1163), PTEN (Ser 380); Medial entorhinal cortex: GSK $3 \alpha$ (Ser 21), IGF1R (Tyr 1135/1136), IRS1 (Ser 636), RP 56 (Ser 235/236)] (Hoffman et al., 2019). In agreement with these findings, the 
Akt/mTOR pathway was reported to respond selectively in a brain region-specific manner in a binge-intake alcohol dependent AUD model (Laguesse et al., 2017). Numerous other studies also have explored the function of mTOR kinases, including in mTORC1 and mTORC2 in alcohol-dependent AUD models (Beckley et al., 2016; Laguesse et al., 2017, 2018; Morisot et al., 2018; For review, Hanim et al., 2020). Future studies should extend the work of Hoffman et al. (2019) in alcohol-dependent models as factors such as blood alcohol level, animal strain, and even brain regions could greatly influence the changes in Akt/mTOR signaling pathway.

Expression of TLR7, HMGB1, and microglia activation marker (CD11b) are increased in post-mortem human alcoholic hippocampal tissue and expression of TLR7 was correlated with alcohol intake. Consistent with human findings, TLR7, HMGB1, IL-1 $\beta$, TNF- $\alpha$, and let-b are also highly expressed in rat HEC brain slice culture following alcohol intake. Alcohol increased the release of let-7b (endogenous ligand for TLR7) in microglia-derived microvesicles and binding of let- $7 \mathrm{~b}$ to the chaperone HMGB1 and DAMP, and reduced the binding of let$7 \mathrm{~b}$ to its classical target, Ago2. Together, the findings suggest that alcohol may mediate hippocampal neurodegeneration via let-7b/HMGB1/TLR7-associated signaling pathways (Coleman et al., 2017). MicroRNA let-7b is highly expressed in CSF of $\mathrm{AD}$ patients (Derkow et al., 2018). Intrathecal injection of CSF from $\mathrm{AD}$ patients (containing highly expressed let-7b) into the CSF of wild-type mice resulted in neurodegeneration, whereas injection into CSF of mice lacking TLR7 did not result in neurodegeneration, suggesting the pivotal role of microRNAs such as let-7b in TLR7 signaling mediated CNS damage (Lehmann et al., 2012; Figure 3).

\section{Parkinson's Disease}

Low to moderate consumption of beer is associated with lower risk of PD (Liu et al., 2013; Zhang D. et al., 2014), and higher liquor consumption was correlated with higher PD risk (Liu et al., 2013). However, the inverse association between low to moderate consumption of beer and lower risk of PD was only seen in males, but not females (Zhang D. et al., 2014). The protective effects of beer on PD-associated risk could be due to elevated serum uric acid level as PD was inversely associated with uric acid level, in males (Weisskopf et al., 2007). While on the contrary, higher content of pure ethanol in liquor (Cao and Prior, 2000), could act as a pro-oxidant and induce pro-inflammatory events (Mann and Folts, 2004; Liu et al., 2013). A more recent metaanalysis reported methodological weaknesses in the past studies associating alcohol intake and PD (16 articles) such as lack of statistical power, residual confounding factor, selection and recall bias, and therefore reported weak association between alcohol consumption and PD in those studies (Bettiol et al., 2015).

Apart from epidemiological associations, genetic approach also attempted to relate alcohol intake with PD. Variants in genes encoding for alcohol dehydrogenease, such as ADH1B rs1229984T was associated with increased risk of PD in women (García-Martín et al., 2019), and similar association was made with ADH4 (Buervenich et al., 2000), and ADH1C (Buervenich et al., 2005). Conversely, others found no such associations (Tan et al., 2001; Kim et al., 2020). $\alpha$-Synuclein is a presynaptic neuronal protein that causes seeding of aggregation on neighboring cells contributing to progression of $\mathrm{PD}$, also highly expressed in AUD patients (14.33 ng/ml; SD, $13.01 \mathrm{ng} / \mathrm{ml}$ ) compared to healthy control $(5.92 \mathrm{ng} / \mathrm{ml} ; \mathrm{SD}, 9.72 \mathrm{ng} / \mathrm{ml})$ (Bönsch et al., 2005). In line with this, correlation between variation in SCNA gene (encoding for $\alpha$-Synuclein) and alcohol craving was made, but not alcohol dependence, suggesting that the variation in the gene is not universal among heavy drinkers (Foroud et al., 2007). Some studies found no correlation between SCNA variations with alcohol dependence (Clarimon et al., 2007; Brighina et al., 2009). Although the exact role of $\alpha$-synuclein in PD pathogenesis is not well delineated, prior studies demonstrated that it may restrict mobility of synaptic vesicles, hence disrupting the release of neurotransmitters via vesicular monoamine transporter (VMAT2) mediated activity (Nemani et al., 2010; Scott et al., 2010; Diao et al., 2013). The hallmark feature of PD pathophysiology is depletion of dopamine secreting neurons in the substantia nigra pars compacta of the basal ganglia and the presence of Lewy bodies (aggregated form of $\alpha$-synuclein) (Davie, 2008). Dopaminergic neuron from substantia nigra pars compacta is one of the components of mesocorticolimbic system that facilitates reinforcing effects of many drugs, including alcohol (Arias-Carrión et al., 2010). Even though alcohol increases dopamine release at early stage of AUD, chronic drinking is detrimental to nigrostriatal dopaminergic neurons (Gilman et al., 1998; Eriksson et al., 2013). In line with this, VMAT2 was shown to be transiently increased during the early drug response (Boileau et al., 2008), and decreased in striatal regions such as the caudate nucleus, and putamen following chronic alcohol intake (Gilman et al., 1998), indicating lasting damage to striatal neuronal terminals in AUD. These findings were further corroborated by a preclinical work where Parkinson rats (induced by intraperitoneal injection of 1-Methyl4-phenyl-1,2,3,6- tetrahydropyridine, $20 \mathrm{mg} / \mathrm{kg}$ ) recorded the highest depletion in dopamine concentration and highest lipid peroxidation activity following 60 days of oral intake of alcohol compared to cigarette inhalation or frequent mating (Ambhore et al., 2012; Figure 4).

\section{Alcohol: Could It Be Neuroprotective?}

A plethora of studies have reported that alcohol consumption is detrimental to health and contributes to cognitive deficits and neurodegeneration (Crews and Nixon, 2009) and increases the risk of developing neurodegenerative disorders such as $\mathrm{AD}$ (Harwood et al., 2010) and PD (Liu et al., 2013). On the contrary, a growing number of contemporary findings have addressed low to moderate consumption of alcohol to have neuroprotective effects (McCarter et al., 2017) and reduces the risk associated with neurodegenerative disorders (Liu et al., 2013; Zhang D. et al., 2014). Various factors were reported to determine the neuroprotective and neurodegenerative properties of alcohol, including the types of beverage consumed (beer vs wine vs liquor), amount of alcohol intake, blood alcohol level (low vs moderate vs high), nutrient deficiency and genetic components. Alcoholic beverages with lower concentration of ethanol such as beer, when taken in low or moderate amount reduce the risk of developing AD (Mukamal et al., 2003; Kok et al., 2016) and PD (Liu et al., 2013; Zhang D. et al., 2014). Compounds such 


\section{Alzheimer's Disease}

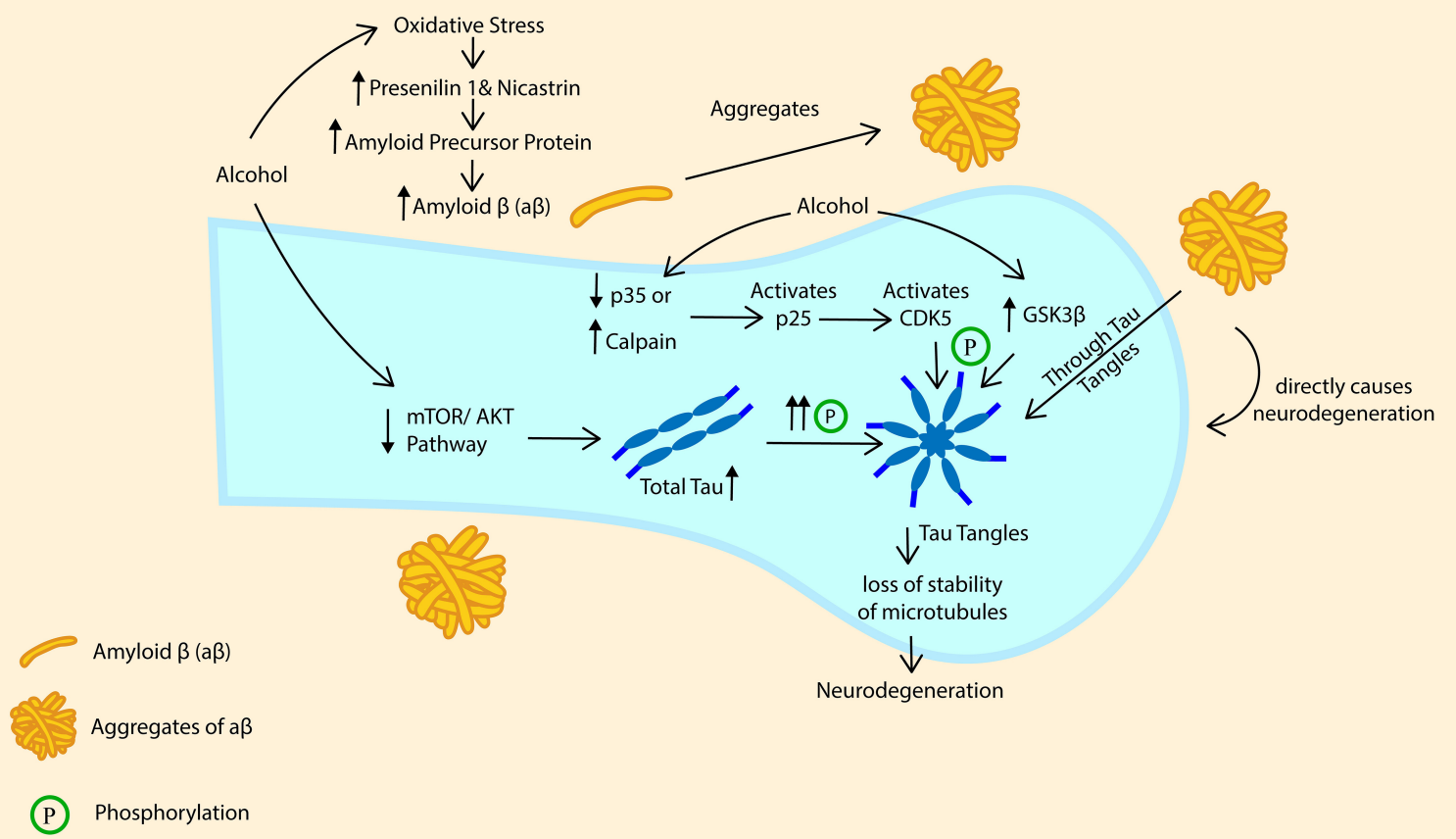

FIGURE 3 | Potential association between Alcohol Use Disorder and manifestation of Alzheimer's disease (AD). Chronic alcohol intake triggers oxidative stress, increases amyloid precursor protein (APP), presenilin (PS1) and nicastrin expression that serves as a basis for amyloid $\beta$ (a $\beta$ ) production and a $\beta$ aggregates. Chronic alcohol intake reduces phosphorylation of proteins associated with mTOR/AKT pathway and increases total tau expression. Chronic alcohol activates CDK5 and Glycogen synthase kinase-3 $\beta$ (GSK3 $\beta$ ) and hyperphosphorylates Tau protein into Tau tangles. Aggregates of a $\beta$ directly causes neurodenegeration and also through tau tangles. Hyperphosphorylation of tau proteins results in loss of microtubule stability, causing neurodegeneration.

as purine, niacin, folic acid, and other phenolic compounds in beer were thought to mediate the neuroprotective effects of alcohol (Sánchez-Muniz et al., 2019). Red wine, known to have high antioxidants, when consumed at low or moderate level for eight weeks (blood alcohol level: 13.9-6.9 mM) reduced microglial activation, expression of pro-inflammatory cytokines, inflammatory mediators, post-ischemic neurotrophil infiltration in a rat focal cerebral ischemic model. However, the same study also reported that the red wine failed to produce better neuroprotective effects compared to another group of rats that was given equivalent amount of ethanol $(13.5 \%, 1.4 \mathrm{~g} / \mathrm{kg} /$ day), suggesting that the neuroprotective effects of low alcohol consumption was due to amount of alcohol consumed rather than the nutritional discrepancy between the beverages (McCarter et al., 2017). Even though animal models of alcohol liquid diet indicate that nutritional deficiency has little to do with ethanol-induced neurodegeneration (Crews and Nixon, 2009), human studies report the opposite, where numerous neurological and psychiatric manifestations in alcohol dependent patients were associated with chronic malnutrition
(Arts et al., 2017). At present, alcohol intoxication is one of the consistently associated factors with alcohol-induced brain damage in animal models (Crews and Nixon, 2009). Binge intake (8.3 - $9.7 \mathrm{~g} / \mathrm{kg} /$ day; serum ethanol level: 250-400 mg\%) (Crews et al., 2004; Tajuddin et al., 2014), chronic intermittent access to alcohol (20\% v/v in tap water for 26 weeks, 5$6 \mathrm{~g} / \mathrm{kg}$ intake per session) (Charlton et al., 2019) have been associated with alcohol-induced neurodegeneration. Equally, in humans, consumption of beverages with high ethanol content such as hard liquor was associated with higher rate of cognitive decline (Heymann et al., 2016) and PD risk (Liu et al., 2013). In reality, most of the alcohol dependent patients practice episodic drinking pattern with more than one type of alcoholic drinks, therefore assessment of the effects of any specific types of alcohol containing drinks on their cognitive performance or neurological features is nearly impossible. In addition, rate of alcohol metabolism also varies among the individuals and impairment in metabolism of aldehydes (one of the byproducts of ethanol metabolism) due to mutation in aldehyde dehydrogenase 2 (ALDH2) was identified as a risk factor for 


\section{Parkinson's Disease}

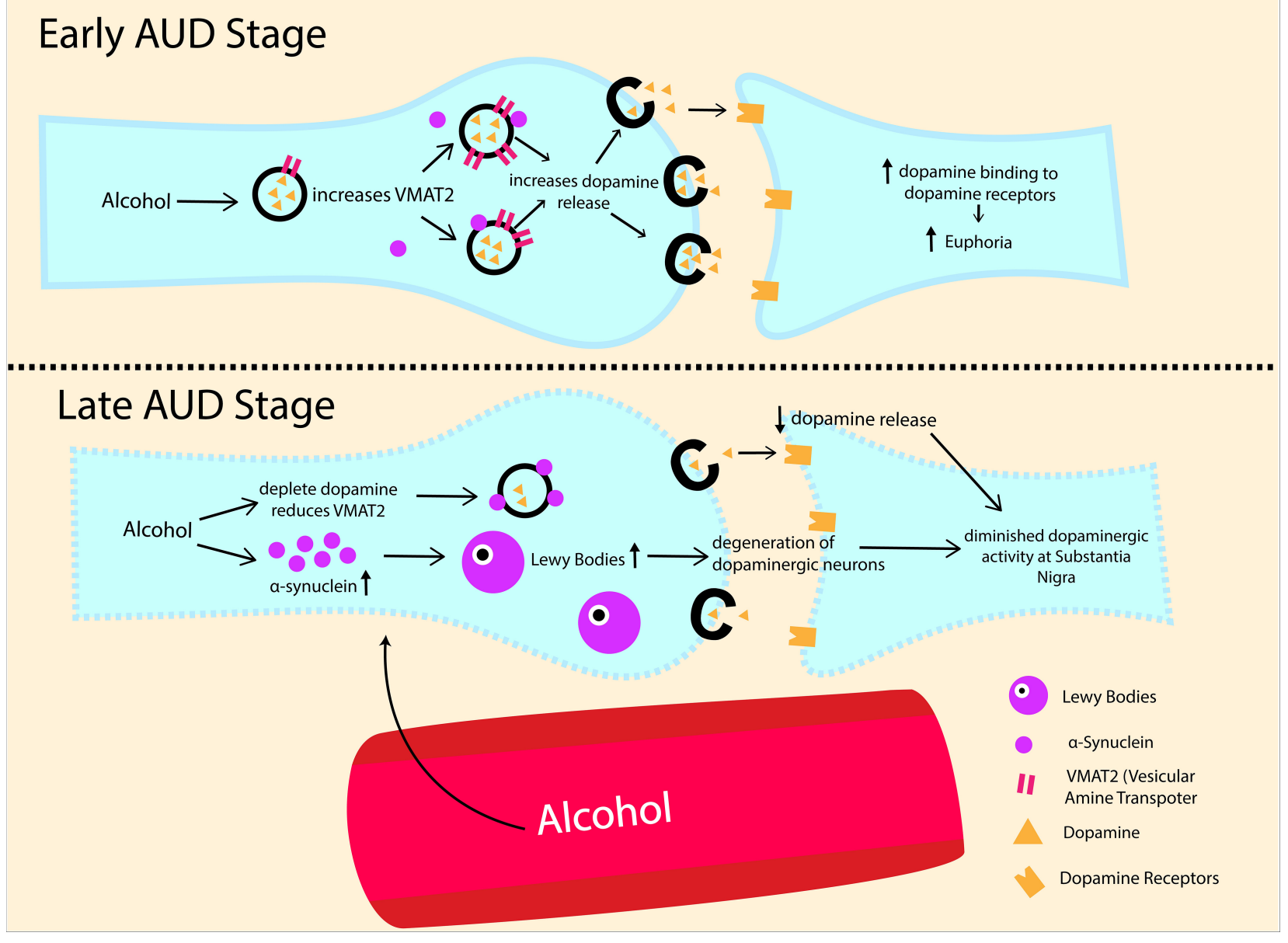

FIGURE 4 | Potential association between Alcohol Use Disorder and development of Parkinson's disease (PD). Increase in $\alpha$-synuclein production and nigrostriatal dopaminergic neurodegeneration contribute to Parkinson's disease (PD) progression. At early stage of AUD, alcohol consumption transiently increases vesicular monoamine transporter (VMAT2) activity and dopamine release in nigrostriatal reward pathway. Chronic binge alcohol intake exhausts dopamine content and consequently reducing VMAT2 activity in striatal neurons (caudate putamen and nucleus). Increased expression of $\alpha$-synuclein in AUD also restricts the release of dopaminergic synaptic vesicles via reduced (VMAT2) activity. Chronic alcohol intake causes $\alpha$-synuclein aggregation, leading to formation of Lewy bodies, which eventually results in degeneration of dopaminergic neurons at substantia niagra.

$\mathrm{AD}$ and PD (Chen et al., 2019; Joshi et al., 2019). Even though the growing body of literature suggests the potential neuroprotective effects of low to moderate dose of ethanol, factors such as genetic variation in metabolism of ethanol should be further explored in its role of neuroinflammation and neurodegeneration.

\section{CONCLUSION}

Excessive oxidative stress is the impetus to alcohol-induced neurodegeneration and further exacerbated by excitotoxicity and neuroimmune response. Chronic binge alcohol intake accentuates glutamatergic excitatory neurotransmission directly or through HPA-axis dysfunction, resulting in neurotoxicity, especially during acute alcohol withdrawal. However, findings show that heightened glutamatergic neurotransmission recovers when the abstinence (sobriety) period is prolonged or even downregulated during craving, which leaves us to wonder about the "seriousness" of glutamatergic excitotoxicity in alcoholinduced neurotoxicity. In contrast, findings on inflammatory markers indicate that alcohol-induced neuroinflammation could mediate neurotoxicity through necrotic and apoptotic cellular cascades. It is still not clear whether microglia is the dominant player in alcohol-induced neuroinflammation, since astrocytes, neurons, and even endothelial cells express immune receptors, nonetheless, not as widely explored as the microglia in AUD. At present, the link between AUD and AD or PD is still vague at the 
clinical level. Prevalence of familial AD and PD cases outnumbers the sporadic events. Therefore, future studies should look into how alcohol-induced changes at the cellular level could promote expression of pro-AD or PD genes.

\section{AUTHOR CONTRIBUTIONS}

HK and JK contributed to the conceptual framework, design, and draft manuscript. $\mathrm{AU}$ and $\mathrm{AH}$ searched references. HK

\section{REFERENCES}

Abraham, I. M., Harkany, T., Horvath, K. M., and Luiten, P. G. M. (2001). Action of glucocorticoids on survival of nerve cells: Promoting neurodegeneration or neuroprotection? J. Neuroendocrinol. 13, 749-760. doi: 10.1046/j.1365-2826. 2001.00705.x

Adinoff, B., Ruether, K., Krebaum, S., Iranmanesh, A., and Williams, M. J. (2003). Increased salivary cortisol concentrations during chronic alcohol intoxication in a naturalistic clinical sample of men. Alcohol. Clin. Exp. Res. 27, 1420-1427. doi: 10.1097/01.ALC.0000087581.13912.64

Afonso, M. B., Rodrigues, P. M., Carvalho, T., Caridade, M., Borralho, P., CortezPinto, H., et al. (2015). Necroptosis is a key pathogenic event in human and experimental murine models of non-alcoholic steatohepatitis. Clin. Sci. 129, 721-739. doi: 10.1042/CS20140732

Akkus, F., Mihov, Y., Treyer, V., Ametamey, S. M., Johayem, A., Senn, S., et al. (2018). Metabotropic glutamate receptor 5 binding in male patients with alcohol use disorder. Transl. Psychiatry 8:17. doi: 10.1038/s41398-017-0066-6

Ambhore, N. S., Mali, J. K., Kanhed, A. M., Antony, S., Bhalerao, A. R., and Bhojraj, S. (2012). Pharmacological and biochemical interventions of cigarette smoke, alcohol, and sexual mating frequency on idiopathic rat model of Parkinson's disease. J. Young Pharm. 4, 177-183. doi: 10.4103/0975-1483.100026

Arias-Carrión, O., Stamelou, M., Murillo-Rodríguez, E., Menéndez-González, M., and Pöppel, E. (2010). Dopaminergic reward system: a short integrative review. Int. Arch. Med. 3:24. doi: 10.1186/1755-7682-3-24

Arts, N. J., Walvoort, S. J., and Kessels, R. P. (2017). Korsakoff's syndrome: a critical review. Neuropsychiatr. Dis. Treat. 13, 2875-2890. doi: 10.2147/NDT.S130078

Ayers-Ringler, J. R., Jia, Y. F., Qiu, Y. Y., and Choi, D. S. (2016). Role of astrocytic glutamate transporter in alcohol use disorder. World J. Psychiatry 6, 31-42. doi: 10.5498/wjp.v6.i1.31

Barnes, J., Ridgway, G. R., Bartlett, J., Henley, S. M., Lehmann, M., Hobbs, N., et al. (2010). Head size, age and gender adjustment in MRI studies: a necessary nuisance? Neuroimage 53, 1244-1255. doi: 10.1016/j.neuroimage.2010.06.025

Beckley, J. T., Laguesse, S., Phamluong, K., Morisot, N., Wegner, S. A., and Ron, D. (2016). The first alcohol drink triggers mTORC1-dependent synaptic plasticity in nucleus accumbens dopamine D1 receptor neurons. J. Neurosci. 36, 701-713. doi: 10.1523/JNEUROSCI.2254-15.2016

Benveniste, E. N., Sparacio, S. M., Norris, J. G., Grennett, H. E., and Fuller, G. M. (1990). Induction and regulation of interleukin-6 gene expression in rat astrocytes. J. Neuroimmunol. 30, 201-212. doi: 10.1016/0165-5728(90)90104-U

Bettiol, S. S., Rose, T. C., Hughes, C. J., and Smith, L. A. (2015). Alcohol consumption and Parkinson's disease risk: a review of recent findings. J. Parkinsons Dis. 5, 425-442. doi: 10.3233/JPD-150533

Bhat, A. H., Dar, K. B., Anees, S., Zargar, M. A., Masood, A., Sofi, M. A., et al. (2015). Oxidative stress, mitochondrial dysfunction and neurodegenerative diseases; a mechanistic insight. Biomed. Pharmacother. 74, 101-110. doi: 10.1016/j.biopha. 2015.07.025

Boileau, I., Rusjan, P., Houle, S., Wilkins, D., Tong, J., Selby, P., et al. (2008). Increased vesicular monoamine transporter binding during early abstinence in human methamphetamine users: Is VMAT2 a stable dopamine neuron biomarker? J. Neurosci. 28, 9850-9856. doi: 10.1523/JNEUROSCI.3008-08. 2008

Boland, B., Yu, W. H., Corti, O., Mollereau, B., Henriques, A., Bezard, E., et al. (2018). Promoting the clearance of neurotoxic proteins in neurodegenerative contributed to the preparation of figure. IM, GT, AU, AH, SI, MS, RM, and JK critically revised the manuscript. All authors contributed to the article and approved the submitted version.

\section{FUNDING}

The authors would like to thank Dr. Ernie for critically reviewing the manuscript. This study was supported by the FF-2020-032 and FF-2019-434/1.

disorders of ageing. Nat. Rev. Drug Discov. 17, 660-688. doi: 10.1038/nrd.20 18.109

Bönsch, D., Greifenberg, V., Bayerlein, K., Biermann, T., Reulbach, U., Hillemacher, T., et al. (2005). $\alpha$-Synuclein protein levels are increased in alcoholic patients and are linked to craving. Alcohol. Clin. Exp. Res. 29, 763-765. doi: 10.1097/01.ALC.0000164360.43907.24

Brighina, L., Schneider, N. K., Lesnick, T. G., de Andrade, M., Cunningham, J. M., Mrazek, D., et al. (2009). $\alpha$-Synuclein, alcohol use disorders, and Parkinson disease: a case-control study. Parkinsonism Relat. Disord. 15, 430-434. doi: 10.1016/j.parkreldis.2008.11.011

Buervenich, S., Carmine, A., Galter, D., Shahabi, H. N., Johnels, B., Holmberg, B., et al. (2005). A rare truncating mutation in ADH1C (G78Stop) shows significant association with Parkinson disease in a large international sample. Arch. Neurol. 62, 74-78. doi: 10.1001/archneur.62.1.74

Buervenich, S., Sydow, O., Carmine, A., Zhang, Z., Anvret, M., and Olson, L. (2000). Alcohol dehydrogenase alleles in Parkinson's disease. Mov. Disord. 15, 813-818. doi: 10.1002/1531-8257(200009)15:5<813::aid-mds1008>3.0.co;2-y

Camp, M. C., Mayfield, R. D., McCracken, M., McCracken, L., and Alcantara, A. A. (2006). Neuroadaptations of Cdk5 in cholinergic interneurons of the nucleus accumbens and prefrontal cortex of inbred alcohol-preferring rats following voluntary alcohol drinking. Alcohol. Clin. Exp. Res. 30, 1322-1335. doi: 10.1111/j.1530-0277.2006.00160.x

Cao, G., and Prior, R. L. (2000). Red wine in moderation: potential health benefits independent of alcohol. Nutr. Clin. Care 3, 76-82. doi: 10.1046/j.1523-5408. 2000.00024.x

Chandrasekar, R. (2013). Alcohol and NMDA receptor: current research and future direction. Front. Mol. Neurosci. 6:14. doi: 10.3389/fnmol.2013.00014

Charlton, A. J., May, C., Luikinga, S. J., Burrows, E. L., Kim, J. H., Lawrence, A. J., et al. (2019). Chronic voluntary alcohol consumption causes persistent cognitive deficits and cortical cell loss in a rodent model. Sci. Rep. 9:18651. doi: 10.1038/s41598-019-55095-w

Chen, C. H., Walker, J., Momenan, R., Rawlings, R., Heilig, M., and Hommer, D. W. (2012). Relationship between liver function and brain shrinkage in patients with alcohol dependence. Alcohol. Clin. Exp. Res. 36, 625-632. doi: 10.1111/j.15300277.2011.01662.x

Chen, J., Huang, W., Cheng, C. H., Zhou, L., Jiang, G. B., and Hu, Y. Y. (2019). Association between aldehyde dehydrogenase-2 polymorphisms and risk of Alzheimer's Disease and Parkinson's Disease: a meta-analysis based on 5,315 individuals. Front Neurol. 10:290. doi: 10.3389/fneur.2019. 00290

Clarimon, J., Gray, R. R., Williams, L. N., Enoch, M. A., Robin, R. W., Albaugh, B., et al. (2007). Linkage disequilibrium and association analysis of $\alpha$-synuclein and alcohol and drug dependence in two american indian populations. Alcohol. Clin. Exp. Res. 31, 546-554. doi: 10.1111/j.1530-0277.2007. 00338.x

Coleman, L. G., and Crews, F. T. (2018). Innate immune signaling and alcohol use disorders. Handb. Exp. Pharmacol. 248, 369-396. doi: 10.1007/164_2018_92

Coleman, L. G., Zou, J., and Crews, F. T. (2017). Microglial-derived miRNA let-7 and HMGB1 contribute to ethanol-induced neurotoxicity via TLR7. J. Neuroinflammation 14:22. doi: 10.1186/s12974-017-0799-4

Collins, M. A., and Neafsey, E. J. (2016). Alcohol, excitotoxicity and adult brain damage: an experimentally unproven chain-of-events. Front Mol Neurosci. 9:8. doi: $10.3389 /$ fnmol.2016.00008 
Conrad, C. D., McLaughlin, K. J., Harman, J. S., Foltz, C., Wieczorek, L., Lightner, E., et al. (2007). Chronic glucocorticoids increase hippocampal vulnerability to neurotoxicity under conditions that produce CA3 dendritic retraction but fail to impair spatial recognition memory. J. Neurosci. 27, 8278-8285. doi: 10.1523/JNEUROSCI.2121-07.2007

Cornford, E. M., Braun, L. D., Oldendorf, W. H., and Hill, M. A. (1982). Comparison of lipid-mediated blood-brain-barrier penetrability in neonates and adults. Am. J. Physiol. Cell Physiol. 243, C161-C168. doi: 10.1152/ajpcell. 1982.243.3.C161

Crews, F. T., Collins, M. A., Dlugos, C., Littleton, J., Wilkins, L., Neafsey, E. J., et al. (2004). Alcohol-induced neurodegeneration: when, where and why? Alcohol. Clin. Exp. Res. 28, 350-364. doi: 10.1097/01.ALC.0000113416.65546.01

Crews, F. T., and Nixon, K. (2009). Mechanisms of neurodegeneration and regeneration in alcoholism. Alcohol Alcohol. 44, 115-127. doi: 10.1093/alcalc/ agn079

Crews, F. T., Sarkar, D. K., Qin, L., Zou, J., Boyadjieva, N., and Vetreno, R. P. (2015). Neuroimmune function and the consequences of alcohol exposure. Alcohol. Res. 37, 331-351.

Davie, C. A. (2008). A review of Parkinson's disease. Br. Med. Bull. 86, 109-127. doi: 10.1093/bmb/ldn013

De la Monte, S. M. (1988). Disproportionate atrophy of cerebral white matter in chronic alcoholics. Arch. Neurol. 45, 990-992. doi: 10.1001/archneur.1988. 00520330076013

De la Monte, S. M., and Kril, J. J. (2014). Human alcohol-related neuropathology. Acta Neuropathol. 127, 71-90. doi: 10.1007/s00401-013-1233-3

Derkow, K., Rössling, R., Schipke, C., Krüger, C., Bauer, J., Fähling, M., et al. (2018). Distinct expression of the neurotoxic microRNA family let-7 in the cerebrospinal fluid of patients with Alzheimer's disease. PLoS One 13:e0200602. doi: 10.1371/journal.pone.0200602

Diao, J., Burré, J., Vivona, S., Cipriano, D. J., Sharma, M., Kyoung, M., et al. (2013). Native $\alpha$-synuclein induces clustering of synaptic-vesicle mimics via binding to phospholipids and synaptobrevin-2/VAMP2. eLife 2:e00592. doi: 10.7554/eLife. 00592.001

Doremus-Fitzwater, T. L., Buck, H. M., Bordner, K., Richey, L., Jones, M. E., and Deak, T. (2014). Intoxication-and withdrawal-dependent expression of central and peripheral cytokines following initial ethanol exposure. Alcohol. Clin. Exp. Res. 38, 2186-2198. doi: 10.1111/acer.12481

Doremus-Fitzwater, T. L., Gano, A., Paniccia, J. E., and Deak, T. (2015). Male adolescent rats display blunted cytokine responses in the CNS after acute ethanol or lipopolysaccharide exposure. Physiol. Behav. 148, 131-144. doi: 10. 1016/j.physbeh.2015.02.032

Dwivedi, D. K., Kumar, D., Kwatra, M., Pandey, S. N., Choubey, P., Lahkar, M., et al. (2018). Voluntary alcohol consumption exacerbated high fat dietinduced cognitive deficits by NF-кB-calpain dependent apoptotic cell death in rat hippocampus: ameliorative effect of melatonin. Biomed. Pharmacother. 108, 1393-1403. doi: 10.1016/j.biopha.2018.09.173

Ende, G., Hermann, D., Demirakca, T., Hoerst, M., Tunc-Skarka, N., WeberFahr, W., et al. (2013). Loss of control of alcohol use and severity of alcohol dependence in non-treatment-seeking heavy drinkers are related to lower glutamate in frontal white matter. Alcohol. Clin. Exp. Res. 37, 1643-1649. doi: 10.1111/acer.12149

Erickson, K., Drevets, W., and Schulkin, J. (2003). Glucocorticoid regulation of diverse cognitive functions in normal and pathological emotional states. Neurosci. Biobehav. Rev. 27, 233-246. doi: 10.1016/S0149-7634(03)00033-2

Eriksson, A. K., Löfving, S., Callaghan, R. C., and Allebeck, P. (2013). Alcohol use disorders and risk of Parkinson's disease: findings from a Swedish national cohort study 1972-2008. BMC Neurol. 13:190. doi: 10.1186/1471-237713-190

Errico, A. L., King, A. C., Lovallo, W. R., and Parsons, O. A. (2002). Cortisol dysregulation and cognitive impairment in abstinent male alcoholics. Alcohol. Clin. Exp. Res. 26, 1198-1204. doi: 10.1111/j.1530-0277.2002.tb02656.x

Fang, H. (2017). [P1-084]: LONG-TERM DRINKING INDUCES TAU HYPERPHOSPHORYLATION AND COGNITIVE DEFICIT. Alzheimers Dement. 13, 270-270. doi: 10.1016/j.jalz.2017.06.151

Fischer, R., and Maier, O. (2015). Interrelation of oxidative stress and inflammation in neurodegenerative disease: role of TNF. Oxid. Med. Cell. Longev. 2015:610813. doi: $10.1155 / 2015 / 610813$
Foroud, T., Wetherill, L. F., Liang, T., Dick, D. M., Hesselbrock, V., Kramer, J., et al. (2007). Association of alcohol craving with $\alpha$-synuclein (SNCA). Alcohol. Clin. Exp. Res. 31, 537-545. doi: 10.1111/j.1530-0277.2007.00337.x

Frank, M. G., Weber, M. D., Watkins, L. R., and Maier, S. F. (2015). Stress sounds the alarmin: the role of the danger-associated molecular pattern HMGB1 in stress-induced neuroinflammatory priming. Brain Behav. Immun. 48, 1-7. doi: 10.1016/j.bbi.2015.03.010

Fratiglioni, L., Ahlbom, A., Viitanen, M., and Winblad, B. (1993). Risk factors for late-onset Alzheimer's disease: a population-based, case-control study. Ann. Neurol. 33, 258-266. doi: 10.1002/ana.410330306

Freund, G., and Anderson, K. J. (1996). Glutamate receptors in the frontal cortex of alcoholics. Alcohol. Clin. Exp. Res. 20, 1165-1172. doi: 10.1111/j.1530-0277. 1996.tb01106.x

Fricker, M., Tolkovsky, A. M., Borutaite, V., Coleman, M., and Brown, G. C. (2018). Neuronal cell death. Physiol. Rev. 98, 813-880. doi: 10.1152/physrev.00011. 2017

Frischknecht, U., Hermann, D., Tunc-Skarka, N., Wang, G. Y., Sack, M., van Eijk, J., et al. (2017). Negative association between MR-spectroscopic glutamate markers and gray matter volume after alcohol withdrawal in the hippocampus: a translational study in humans and rats. Alcohol. Clin. Exp. Res. 41, 323-333. doi: 10.1111/acer.13308

García, A. M., Ramón-Bou, N., and Porta, M. (2010). Isolated and joint effects of tobacco and alcohol consumption on risk of Alzheimer's disease. J. Alzheimers Dis. 20, 577-586. doi: 10.3233/JAD-2010-1399

García-Martín, E., Diez-Fairen, M., Pastor, P., Gómez-Tabales, J., Alonso-Navarro, H., Alvarez, I., et al. (2019). Association between the missense alcohol dehydrogenase rs1229984T variant with the risk for Parkinson's disease in women. J. Neurol. 266, 346-352. doi: 10.1007/s00415-018-9136-9

García-Suástegui, W. A., Ramos-Chávez, L. A., Rubio-Osornio, M., CalvilloVelasco, M., Atzin-Méndez, J. A., Guevara, J., et al. (2017). The Role of CYP2E1 in the drug metabolism or bioactivation in the brain. Oxid. Med. Cell. Longev. 2017:4680732. doi: 10.1155/2017/4680732

Gilman, S., Koeppe, R. A., Adams, K. M., Junck, L., Kluin, K. J., Johnson-Greene, D., et al. (1998). Decreased striatal monoaminergic terminals in severe chronic alcoholism demonstrated with $(+)[11 \mathrm{C}]$ dihydrotetrabenazine and positron emission tomography. Ann. Neurol. 44, 326-333. doi: 10.1002/ana.410440307

Gorky, J., and Schwaber, J. (2016). The role of the gut-brain axis in alcohol use disorders. Prog. Neuropsychopharmacol. 65, 234-241. doi: 10.1016/j.pnpbp. 2015.06.013

Grimes, C. A., and Jope, R. S. (2001). The multifaceted roles of glycogen synthase kinase $3 \beta$ in cellular signaling. Prog. Neurobiol. 65, 391-426. doi: 10.1016/ S0301-0082(01)00011-9

Guerri, C., and Grisolia, S. (1980). Changes in glutathione in acute and chronic alcohol intoxication. Pharmacol. Biochem. Behav. 13, 53-61. doi: 10.1016/ S0091-3057(80)80009-8

Hanim, A., Mohamed, I. N., Mohamed, R. M. P., Das, S., Nor, N. S. M., Harun, R. A., et al. (2020). mTORC and PKCE in regulation of alcohol use disorder. Mini Rev. Med. Chem. doi: 10.2174/1389557520666200624122325 [Epub ahead of print].

Harper, C., and Matsumoto, I. (2005). Ethanol and brain damage. Curr. Opin. Pharmacol. 5, 73-78. doi: 10.1016/j.coph.2004.06.011

Harper, C. G., Kril, J. J., and Holloway, R. L. (1985). Brain shrinkage in chronic alcoholics: a pathological study. Br. Med. J. 290, 501-504. doi: 10.1136/bmj.290. 6467.501

Harwood, D. G., Barker, W. W., Loewenstein, D. A., Ownby, R. L., GeorgeHyslop, P. S., Mullan, M., et al. (1999). A cross-ethnic analysis of risk factors for AD in white Hispanics and white non-Hispanics. Neurology 52, 551-551. doi: 10.1212/WNL.52.3.551

Harwood, D. G., Kalechstein, A., Barker, W. W., Strauman, S., St. George-Hyslop, P., Iglesias, C., et al. (2010). The effect of alcohol and tobacco consumption, and apolipoprotein E genotype, on the age of onset in Alzheimer's disease. Int. J. Geriatr. Psychiatry 25, 511-518. doi: 10.1002/gps.2372

Hermann, D., Weber-Fahr, W., Sartorius, A., Hoerst, M., Frischknecht, U., Tunc-Skarka, N., et al. (2012). Translational magnetic resonance spectroscopy reveals excessive central glutamate levels during alcohol withdrawal in humans and rats. Biol. Psychiatry 71, 1015-1021. doi: 10.1016/j.biopsych.2011. 07.034 
Hernández, J. A., López-Sánchez, R. C., and Rendón-Ramírez, A. (2016). Lipids and oxidative stress associated with ethanol-induced neurological damage. Oxid. Med. Cell. Longev. 2016:1543809. doi: 10.1155/2016/1543809

Heymann, D., Stern, Y., Cosentino, S., Tatarina-Nulman, O., Dorrejo, J. N., and $\mathrm{Gu}, \mathrm{Y}$. (2016). The association between alcohol use and the progression of Alzheimer's disease. Curr. Alzheimer Res. 13, 1356-1362. doi: 10.2174/ 1567205013666160603005035

Hoffman, J. L., Faccidomo, S., Kim, M., Taylor, S. M., Agoglia, A. E., May, A. M., et al. (2019). Alcohol drinking exacerbates neural and behavioral pathology in the 3xTg-AD mouse model of Alzheimer's disease. Int. Rev. Neurobiol. 148, 169-230. doi: 10.1016/bs.irn.2019.10.017

Hu, W., Zhang, Y., Wu, W., Yin, Y., Huang, D., Wang, Y., et al. (2016). Chronic glucocorticoids exposure enhances neurodegeneration in the frontal cortex and hippocampus via NLRP-1 inflammasome activation in male mice. Brain. Behav. Immun. 52, 58-70. doi: 10.1016/j.bbi.2015.09.019

Huang, D., Yu, M., Yang, S., Lou, D., Zhou, W., Zheng, L., et al. (2018). Ethanol alters APP processing and aggravates Alzheimer-associated phenotypes. Mol. Neurobiol. 55, 5006-5018. doi: 10.1007/s12035-017-0703-3

Huang, W. J., Zhang, X., and Chen, W. W. (2016). Association between alcohol and Alzheimer's disease. Exp. Ther. Med. 12, 1247-1250. doi: 10.3892/etm.2016. 3455

Jacquot, C., Croft, A. P., Prendergast, M. A., Mulholland, P., Shaw, S. G., and Little, H. J. (2008). Effects of the glucocorticoid antagonist, mifepristone, on the consequences of withdrawal from long term alcohol consumption. Alcohol. Clin. Exp. Res. 32, 2107-2116. doi: 10.1111/j.1530-0277.2008.00799.x

Jesse, S., Bråthen, G., Ferrara, M., Keindl, M., Ben-Menachem, E., Tanasescu, R., et al. (2017). Alcohol withdrawal syndrome: mechanisms, manifestations, and management. Acta Neurol. Scand. 135, 4-16. doi: 10.1111/ane.12671

Ji, Z., Yuan, L., Lu, X., Ding, H., Luo, J., and Ke, Z. J. (2018). Binge alcohol exposure causes neurobehavioral deficits and GSK3 $\beta$ activation in the hippocampus of adolescent rats. Sci. Rep. 8:3088. doi: 10.1038/s41598-018-21341-w

Joshi, A. U., Van Wassenhove, L. D., Logas, K. R., Minhas, P. S., Andreasson, K. I., Weinberg, K. I., et al. (2019). Aldehyde dehydrogenase 2 activity and aldehydic load contribute to neuroinflammation and Alzheimer's disease related pathology. Acta Neuropathol. Commun. 7:190. doi: 10.1186/s40478-0190839-7

Jin, Z., Bhandage, A. K., Bazov, I., Kononenko, O., Bakalkin, G., Korpi, E. R., et al. (2014). Expression of specific ionotropic glutamate and GABA-A receptor subunits is decreased in central amygdala of alcoholics. Front. Cell. Neurosci. 8:288. doi: $10.3389 /$ fncel.2014.00288

June, H. L., Liu, J., Warnock, K. T., Bell, K. A., Balan, I., Bollino, D., et al. (2015). CRF-amplified neuronal TLR4/MCP-1 signaling regulates alcohol self-administration. Neuropsychopharmacol 40, 1549-1559. doi: 10.1038/npp. 2015.4

Kagan, V. E., Tyurina, Y. Y., Tyurin, V. A., Mohammadyani, D., Angeli, J. P. F., Baranov, S. V., et al. (2015). Cardiolipin signaling mechanisms: collapse of asymmetry and oxidation. Antioxid. Redox Sign. 22, 1667-1680. doi: 10.1089/ ars.2014.6219

Kapogiannis, D., Kisser, J., Davatzikos, C., Ferrucci, L., Metter, J., and Resnick, S. M. (2012). Alcohol consumption and premotor corpus callosum in older adults. Eur. Neuropsychopharmacol. 22, 704-710. doi: 10.1016/j.euroneuro.2012.02.003

Kelso, M. L., Liput, D. J., Eaves, D. W., and Nixon, K. (2011). Upregulated vimentin suggests new areas of neurodegeneration in a model of an alcohol use disorder. Neuroscience 197, 381-393. doi: 10.1016/j.neuroscience.2011.09.019

Kim, G. H., Kim, J. E., Rhie, S. J., and Yoon, S. (2015). The role of oxidative stress in neurodegenerative diseases. Exp. Neurobiol. 24, 325-340. doi: 10.5607/en.2015. 24.4.325

Kim, J. J., Bandres-Ciga, S., Blauwendraat, C., Gan-Or, Z., International Parkinson's, Disease Genomics, et al. (2020). No genetic evidence for involvement of alcohol dehydrogenase genes in risk for Parkinson's disease. Neurobiol. Aging. 87, e19-140.e22. doi: 10.1016/j.neurobiolaging.2019.11.006

Kim, S. R., Jeong, H. Y., Yang, S. H., Choi, S. P., Seo, M. Y., Yun, Y. K., et al. (2011). Effects of chronic alcohol consumption on expression levels of APP and A $\beta$ producing enzymes. BMB Rep. 44, 135-139. doi: 10.5483/BMBRep.2011.44.2. 135

Kim-Campbell, N., Gomez, H., and Bayir, H. (2019). Cell death pathways: apoptosis and regulated necrosis. Crit. Care. Nephrol. 2019, 113-121. doi: 10. 1016/B978-0-323-44942-7.00020-0
Kok, E. H., Karppinen, T. T., Luoto, T., Alafuzoff, I., and Karhunen, P. J. (2016). Beer drinking associates with lower burden of amyloid beta aggregation in the brain: Helsinki Sudden Death Series.". Alcohol. Clin. Exp. Res. 40, 1473-1478. doi: 10.1111/acer.13102

Kryger, R., and Wilce, P. A. (2010). The effects of alcoholism on the human basolateral amygdala. Neuroscience 167, 361-371. doi: 10.1016/j.neuroscience. 2010.01.061

Kumar, J., Hapidin, H., Bee, Y. T. G., and Ismail, Z. (2013). Effects of the mGluR5 antagonist MPEP on ethanol withdrawal induced anxiety-like syndrome in rats. Behav. Brain. Sci. 9:43. doi: 10.1186/1744-9081-9-43

Kumar, J., Hapidin, H., Bee, Y. T. G., and Ismail, Z. (2016). The effects of acute ethanol administration on ethanol withdrawal-induced anxiety-like syndrome in rats: a biochemical study. Alcohol 50, 9-17. doi: 10.1016/j.alcohol.2015.10. 001

Kumar, J., Ismail, Z., Hatta, N. H., Baharuddin, N., Hapidin, H., Get Bee, Y. T., et al. (2018). Alcohol addiction-metabotropic glutamate receptor subtype 5 and its Ligands: How They All Come Together? Curr. Drug Targets 19, 907-915. doi: 10.2174/1389450118666170511144302

Kumar, J., Teoh, S. L., Das, S., and Mahakknaukrauh, P. (2017). Oxidative stress in oral diseases: understanding its relation with other systemic diseases. Front. Physiol. 8:693. doi: 10.3389/fphys.2017.00693

Kusakawa, G. I., Saito, T., Onuki, R., Ishiguro, K., Kishimoto, T., and Hisanaga, S. I. (2000). Calpain-dependent proteolytic cleavage of the p35 cyclin-dependent kinase 5 activator to p25. J. Biol. Chem. 275, 17166-17172. doi: 10.1074/jbc. M907757199

Lafortune, L., Kelly, S., Kuhn, I., Cowan, A., and Brayne, C. (2014). Disability, Dementia and Frailty in Later Life: Mid-Life Approaches to Prevent or Delay the Onset of these Conditions. Report to NICE Public Health Guideline Committee. France: NICE.

Laguesse, S., Morisot, N., Phamluong, K., Sakhai, S. A., and Ron, D. (2018). mTORC2 in the dorsomedial striatum of mice contributes to alcoholdependent F-Actin polymerization, structural modifications, and consumption. Neuropsychopharmacology 43, 1539-1547. doi: 10.1038/s41386-0180012-1

Laguesse, S., Morisot, N., Shin, J. H., Liu, F., Adrover, M. F., Sakhai, S. A., et al. (2017). Prosapip1-dependent synaptic adaptations in the nucleus accumbens drive alcohol intake, seeking, and reward. Neuron 96, 145-159. doi: 10.1016/j. neuron.2017.08.037

Leclercq, S., Cani, P. D., Neyrinck, A. M., Stärkel, P., Jamar, F., Mikolajczak, M., et al. (2012). Role of intestinal permeability and inflammation in the biological and behavioral control of alcohol-dependent subjects. Brain Behav. Immun. 26, 911-918. doi: 10.1016/j.bbi.2012.04.001

Lee, S., Selvage, D., Hansen, K., and Rivier, C. (2004). Site of action of acute alcohol administration in stimulating the rat hypothalamic-pituitary-adrenal axis: comparison between the effect of systemic and intracerebroventricular injection of this drug on pituitary and hypothalamic responses. Endocrinology 145, 4470-4479. doi: 10.1210/en.2004-0110

Lehmann, S. M., Krüger, C., Park, B., Derkow, K., Rosenberger, K., Baumgart, J., et al. (2012). An unconventional role for miRNA: let-7 activates Toll-like receptor 7 and causes neurodegeneration. Nat. Neurosci. 15, 827-835. doi: $10.1038 / \mathrm{nn} .3113$

Liguori, I., Russo, G., Curcio, F., Bulli, G., Aran, L., Della-Morte, D., et al. (2018). Oxidative stress, aging, and diseases. Clin. Interv. Aging 13, 757-772. doi: 10. 2147/CIA.S158513

Linseman, D. A., Butts, B. D., Precht, T. A., Phelps, R. A., Le, S. S., Laessig, T. A., et al. (2004). Glycogen synthase kinase- $3 \beta$ phosphorylates Bax and promotes its mitochondrial localization during neuronal apoptosis. J. Neurosci. 24, 9993-10002. doi: 10.1523/JNEUROSCI.2057-04.2004

Little, H. J., Croft, A. P., O'callaghan, M. J., Brooks, S. P., Wang, G., and Shaw, S. G. (2008). Selective increases in regional brain glucocorticoid: a novel effect of chronic alcohol. Neuroscience 156, 1017-1027. doi: 10.1016/j.neuroscience. 2008.08.029

Liu, R., Guo, X., Park, Y., Wang, J., Huang, X., Hollenbeck, A., et al. (2013). Alcohol consumption, types of alcohol, and Parkinson's disease. PLoS One 8:e66452. doi: 10.1371/journal.pone.0066452

Liu, Y., Chen, G., Ma, C., Bower, K. A., Xu, M., Fan, Z., et al. (2009). Overexpression of glycogen synthase kinase $3 \beta$ sensitizes neuronal cells to ethanol toxicity. J. Neurosci. Res. 87, 2793-2802. doi: 10.1002/jnr.22098 
Lu, C., Xu, W., Zhang, F., Shao, J., and Zheng, S. (2016). Nrf2 knockdown disrupts the protective effect of curcumin on alcohol-induced hepatocyte necroptosis. Mol. Pharm. 13, 4043-4053. doi: 10.1021/acs.molpharmaceut.6b00562

Lucas, J. J., Hernández, F., Gómez-Ramos, P., Morán, M. A., Hen, R., and Avila, J. (2001). Decreased nuclear $\beta$-catenin, tau hyperphosphorylation and neurodegeneration in GSK-3 $\beta$ conditional transgenic mice. EMBO J. 20, 27-39. doi: $10.1093 / \mathrm{emboj} / 20.1 .27$

Luchsinger, J. A., Tang, M. X., Siddiqui, M., Shea, S., and Mayeux, R. (2004). Alcohol intake and risk of dementia. J. Am. Geriatr. Soc. 52, 540-546. doi: 10.1111/j.1532-5415.2004.52159.x

Luo, J. (2009). GSK3 $\beta$ in ethanol neurotoxicity. Mol. Neurobiol. 40, 108-121. doi: $10.1007 / \mathrm{s} 12035-009-8075-\mathrm{y}$

Luo, J. (2010). Lithium-mediated protection against ethanol neurotoxicity. Front. Neurosci. 4:41. doi: 10.3389/fnins.2010.00041

Luo, J. (2012). The role of GSK3beta in the development of the central nervous system. Front. Biol. 7, 212-220. doi: 10.1007/s11515-012-1222-2

MacPherson, A., Dinkel, K., and Sapolsky, R. (2005). Glucocorticoids worsen excitotoxin-induced expression of pro-inflammatory cytokines in hippocampal cultures. Exp. Neurol. 194, 376-383. doi: 10.1016/j.expneurol.2005.02.021

Mann, L. B., and Folts, J. D. (2004). Effects of ethanol and other constituents of alcoholic beverages on coronary heart disease: a review. Pathophysiology 10, 105-112. doi: 10.1016/j.pathophys.2003.10.011

Maragakis, N. J., and Rothstein, J. D. (2006). Mechanisms of disease: astrocytes in neurodegenerative disease. Nat. Clin. Pract. Neurol. 2, 679-689. doi: 10.1038/ ncpneuro0355

Marshall, S. A., Geil, C. R., and Nixon, K. (2016). Prior binge ethanol exposure potentiates the microglial response in a model of alcohol-induced neurodegeneration. Brain Sci. 6:16. doi: 10.3390/brainsci6020016

Marshall, S. A., McClain, J. A., Kelso, M. L., Hopkins, D. M., Pauly, J. R., and Nixon, K. (2013). Microglial activation is not equivalent to neuroinflammation in alcohol-induced neurodegeneration: the importance of microglia phenotype. Neurobiol. Dis. 54, 239-251. doi: 10.1016/j.nbd.2012.12.016

Mayfield, J., Ferguson, L., and Harris, R. A. (2013). Neuroimmune signaling: a key component of alcohol abuse. Curr. Opin. Neurobiol. 23, 513-520. doi: 10.1016/ j.conb.2013.01.024

Maynard, M. E., Barton, E. A., Robinson, C. R., Wooden, J. I., and Leasure, J. L. (2018). Sex differences in hippocampal damage, cognitive impairment, and trophic factor expression in an animal model of an alcohol use disorder. Brain Struct. Funct. 223, 195-210. doi: 10.1007/s00429-017-1482-3

McCarter, K. D., Li, C., Jiang, Z., Lu, W., Smith, H. A., Xu, G., et al. (2017). Effect of low-dose alcohol consumption on inflammation following transient focal cerebral ischemia in rats. Sci. Rep. 7:12547. doi: 10.1038/s41598-017-12720-w

Mirijello, A., D’Angelo, C., Ferrulli, A., Vassallo, G., Antonelli, M., Caputo, F., et al. (2015). Identification and management of alcohol withdrawal syndrome. Drugs 75, 353-365. doi: 10.1007/s40265-015-0358-1

Mohamed, R. M. P., Kumar, J., Ahmad, S. U., and Mohamed, I. N. (2018a). Novel pharmacotherapeutic approaches in treatment of alcohol addiction. Curr. Drug Targets 19, 1378-1390. doi: 10.2174/138945011966618052309 2534

Mohamed, R. M. P., Mokhtar, M. H., Yap, E., Hanim, A., Abdul Wahab, N., Jaffar, F. H., et al. (2018b). Ethanol-induced changes in PKCE: from cell to behavior. Front. Neurosci. 12:244. doi: 10.3389/fnins.2018. 00244

Mon, A., Durazzo, T. C., and Meyerhoff, D. J. (2012). Glutamate, GABA, and other cortical metabolite concentrations during early abstinence from alcohol and their associations with neurocognitive changes. Drug Alcohol Depend. 125, 27-36. doi: 10.1016/j.drugalcdep.2012.03.012

Morisot, N., Novotny, C. J., Shokat, K. M., and Ron, D. (2018). A new generation of mTORC1 inhibitor attenuates alcohol intake and reward in mice. Addict. Biol. 23, 713-722. doi: 10.1111/adb.12528

Morris, S. A., Eaves, D. W., Smith, A. R., and Nixon, K. (2010). Alcohol inhibition of neurogenesis: a mechanism of hippocampal neurodegeneration in an adolescent alcohol abuse model. Hippocampus 20, 596-607. doi: 10.1002/ hipo. 20665

Mukamal, K. J., Kuller, L. H., Fitzpatrick, A. L., Longstreth, W. T. Jr., Mittleman, M. A., and Siscovick, D. S. (2003). Prospective study of alcohol consumption and risk of dementia in older adults. JAMA 289, 1405-1413. doi: 10.1001/jama. 289.11.1405
Mulholland, P. J., Self, R. L., Harris, B. R., Little, H. J., Littleton, J. M., and Prendergast, M. A. (2005). Corticosterone increases damage and cytosolic calcium accumulation associated with ethanol withdrawal in rat hippocampal slice cultures. Alcohol. Clin. Exp. Res. 29, 871-881. doi: 10.1097/01.ALC. 0000163509.27577.DA

Nemani, V. M., Lu, W., Berge, V., Nakamura, K., Onoa, B., Lee, M. K., et al. (2010). Increased expression of $\alpha$-synuclein reduces neurotransmitter release by inhibiting synaptic vesicle reclustering after endocytosis. Neuron 65, 66-79. doi: 10.1016/j.neuron.2009.12.023

Obernier, J. A., Bouldin, T. W., and Crews, F. T. (2002). Binge ethanol exposure in adult rats causes necrotic cell death. Alcohol. Clin. Exp. Res. 26, 547-557. doi: 10.1111/j.1530-0277.2002.tb02573.x

O’Neill, J., Cardenas, V. A., and Meyerhoff, D. J. (2001). Effects of abstinence on the brain: quantitative magnetic resonance imaging and magnetic resonance spectroscopic imaging in chronic alcohol abuse. Alcohol. Clin. Exp. Res. 25, 1673-1682. doi: 10.1111/j.1530-0277.2001.tb02174.x

Ozsoy, S., Durak, A. C., and Esel, E. (2013). Hippocampal volumes and cognitive functions in adult alcoholic patients with adolescent-onset. Alcohol 47, 9-14. doi: 10.1016/j.alcohol.2012.09.002

Peng, H., Nickell, C. R. G., Chen, K. Y., McClain, J. A., and Nixon, K. (2017). Increased expression of M1 and M2 phenotypic markers in isolated microglia after four-day binge alcohol exposure in male rats. Alcohol 62, 29-40. doi: 10.1016/j.alcohol.2017.02.175

Pfefferbaum, A., Sullivan, E. V., Mathalon, D. H., Shear, P. K., Rosenbloom, M. J., and Lim, K. O. (1995). Longitudinal changes in magnetic resonance imaging brain volumes in abstinent and relapsed alcoholics. Alcohol. Clin. Exp. Res. 19, 1177-1191. doi: 10.1111/j.1530-0277.1995.tb01598.x

Piazza-Gardner, A. K., Gaffud, T. J., and Barry, A. E. (2013). The impact of alcohol on Alzheimer's disease: a systematic review. Aging Ment. Health 17, 133-146. doi: 10.1080/13607863.2012.742488

Prendergast, M. A., and Mulholland, P. J. (2012). Glucocorticoid and polyamine interactions in the plasticity of glutamatergic synapses that contribute to ethanol-associated dependence and neuronal injury. Addict. Biol. 17, 209-223. doi: 10.1111/j.1369-1600.2011.00375.x

Prisciandaro, J. J., Schacht, J. P., Prescot, A. P., Renshaw, P. F., Brown, T. R., and Anton, R. F. (2016). Associations between recent heavy drinking and dorsal anterior cingulate $\mathrm{N}$-acetylaspartate and glutamate concentrations in non-treatment-seeking individuals with alcohol dependence. Alcohol. Clin. Exp. Res. 40, 491-496. doi: 10.1111/acer.12977

Qin, L., and Crews, F. T. (2012). NADPH oxidase and reactive oxygen species contribute to alcohol-induced microglial activation and neurodegeneration. J. Neuroinflammation 9:5. doi: 10.1186/1742-2094-9-5

Qin, L., He, J., Hanes, R. N., Pluzarev, O., Hong, J. S., and Crews, F. T. (2008). Increased systemic and brain cytokine production and neuroinflammation by endotoxin following ethanol treatment. J. Neuroinflammation 5:10. doi: 10 . 1186/1742-2094-5-10

Qin, L., Liu, Y., Hong, J. S., and Crews, F. T. (2013). NADPH oxidase and aging drive microglial activation, oxidative stress, and dopaminergic neurodegeneration following systemic LPS administration. Glia 61, 855-868. doi: 10.1002/glia.22479

Rajgopal, Y., and Vemuri, M. C. (2001). Ethanol induced changes in cyclindependent kinase-5 activity and its activators, P35, P67 (Munc-18) in rat brain. . Neurosci. Lett. 308, 173-176. doi: 10.1016/S0304-3940(01)02011-0

Rajgopal, Y., and Vemuri, M. C. (2002). Calpain activation and $\alpha$-spectrin cleavage in rat brain by ethanol. Neurosci. Lett. 321, 187-191. doi: 10.1016/S03043940(02)00063-0

Rao, P. S. S., Bell, R. L., Engleman, E. A., and Sari, Y. (2015). Targeting glutamate uptake to treat alcohol use disorders. Front. Neurosci. 9:144. doi: 10.3389/fnins. 2015.00144

Reddy, V. D., Padmavathi, P., Kavitha, G., Saradamma, B., and Varadacharyulu, N. (2013). Alcohol-induced oxidative/nitrosative stress alters brain mitochondrial membrane properties. Mol. Cell. Biochem. 375, 39-47. doi: 10.1007/s11010012-1526-1

Reyes, T. M., Fabry, Z., and Coe, C. L. (1999). Brain endothelial cell production of a neuroprotective cytokine, interleukin-6, in response to noxious stimuli. Brain Res. 851, 215-220. doi: 10.1016/S0006-8993(99)02189-7

Reynolds, A. R., Berry, J. N., Sharrett-Field, L., and Prendergast, M. A. (2015). Ethanol withdrawal is required to produce persisting $\mathrm{N}$-methyl-D-aspartate 
receptor-dependent hippocampal cytotoxicity during chronic intermittent ethanol exposure. Alcohol 49, 219-227. doi: 10.1016/j.alcohol.2015.01.008

Ringheim, G. E., Burgher, K. L., and Heroux, J. A. (1995). Interleukin-6 mRNA expression by cortical neurons in culture: evidence for neuronal sources of interleukin-6 production in the brain. J. Neuroimmunol. 63, 113-123. doi: 10. 1016/0165-5728(95)00134-4

Roberts, B. J., Song, B. J., Soh, Y., Park, S. S., and Shoaf, S. E. (1995). Ethanol induces CYP2E1 by protein stabilization role of ubiquitin conjugation in the rapid degradation of CYP2E1. J. Biol. Chem. 270, 29632-29635. doi: 10.1074/ jbc. 270.50 .29632

Ruitenberg, A., van Swieten, J. C., Witteman, J. C., Mehta, K. M., van Duijn, C. M., Hofman, A., et al. (2002). Alcohol consumption and risk of dementia: the Rotterdam Study. Lancet 359, 281-286. doi: 10.1016/S0140-6736(02)07493-7

Salin, K., Auer, S. K., Rey, B., Selman, C., and Metcalfe, N. B. (2015). Variation in the link between oxygen consumption and ATP production, and its relevance for animal performance. Proc. Royal Soc. B. 282:20151028. doi: 10.1098/rspb. 2015.1028

Salling, M. C., Faccidomo, S. P., Li, C., Psilos, K., Galunas, C., Spanos, M., et al. (2016). Moderate alcohol drinking and the amygdala proteome: identification and validation of calcium/calmodulin dependent kinase II and AMPA receptor activity as novel molecular mechanisms of the positive reinforcing effects of alcohol. Biol. Psychiatry 79, 430-442. doi: 10.1016/j.biopsych.2014.10.020

Sánchez-Muniz, F. J., Macho-González, A., Garcimartín, A., Santos-López, J. A., Benedí, J., Bastida, S., et al. (2019). The nutritional components of beer and its relationship with neurodegeneration and Alzheimer's disease. Nutrients 11:1558. doi: 10.3390/nu11071558

Sapolsky, R. M. (2000). Glucocorticoids and hippocampal atrophy in neuropsychiatric disorders. Arch. Gen. Psychiatry 57, 925-935. doi: 10.1001/archpsyc.57.10.925

Schöbitz, B., de Kloet, E. R., Sutanto, W., and Holsboer, F. (1993). Cellular localization of interleukin $6 \mathrm{mRNA}$ and interleukin 6 receptor mRNA in rat brain. Eur. J. Neurosci. 5, 1426-1435. doi: 10.1111/j.1460-9568.1993.tb00210.x

Schwarzinger, M., Pollock, B. G., Hasan, O. S., Dufouil, C., Rehm, J., Baillot, S., et al. (2018). Contribution of alcohol use disorders to the burden of dementia in France 2008-13: a nationwide retrospective cohort study. Lancet Public Health 3, e124-e132. doi: 10.1016/S2468-2667(18)30022-7

Scott, D. A., Tabarean, I., Tang, Y., Cartier, A., Masliah, E., and Roy, S. (2010). A pathologic cascade leading to synaptic dysfunction in $\alpha$-synuclein-induced neurodegeneration. J. Neurosci. 30, 8083-8095. doi: 10.1523/JNEUROSCI. 1091-10.2010

Sorrells, S. F., and Sapolsky, R. M. (2007). An inflammatory review of glucocorticoid actions in the CNS. Brain. Behav. Immun. 21, 259-272. doi: 10.1016/j.bbi.2006.11.006

Sullivan, E. V., Marsh, L., Mathalon, D. H., Lim, K. O., and Pfefferbaum, A. (1995). Anterior hippocampal volume deficits in nonamnesic, aging chronic alcoholics. Alcohol. Clin. Exp. Res. 19, 110-122. doi: 10.1111/j.1530-0277.1995.tb01478.x

Szabo, G., and Lippai, D. (2014). Converging actions of alcohol on liver and brain immune signaling. Int. Rev. Neurobiol. 118, 359-380. doi: 10.1016/B978-0-12801284-0.00011-7

Tabakoff, B., Jaffe, R. C., and Ritzmann, R. F. (1978). Corticosterone concentrations in mice during ethanol drinking and withdrawal. J. Pharm. Pharmacol. 30, 371-374. doi: 10.1111/j.2042-7158.1978.tb13259.x

Tajuddin, N., Moon, K. H., Marshall, S. A., Nixon, K., Neafsey, E. J., Kim, H. Y., et al. (2014). Neuroinflammation and neurodegeneration in adult rat brain from binge ethanol exposure: abrogation by docosahexaenoic acid. PLoS One 9:e101223. doi: 10.1371/journal.pone.0101223

Tan, E. K., Nagamitsu, S., Matsuura, T., Khajavi, M., Jankovic, J., Ondo, W., et al. (2001). Alcohol dehydrogenase polymorphism and Parkinson's disease. Neurosci. Lett. 305, 70-72. doi: 10.1016/S0304-3940(01)01770-0

Tyas, S. L., Koval, J. J., and Pederson, L. L. (2000). Does an interaction between smoking and drinking influence the risk of Alzheimer's disease? Results from three Canadian data sets. Stat. Med. 19, 1685-1696. doi: 10.1002/(sici)10970258(20000615/30)19:11/12<1685::aid-sim454>3.0.co;2-\#

Vengeliene, V., Moeller, A., Meinhardt, M. W., Beardsley, P. M., Sommer, W. H., Spanagel, R., et al. (2016). The calpain inhibitor A705253 attenuates alcohol-seeking and relapse with low side-effect profile. Neuropsychopharmacology 41, 979-988. doi: 10.1038/npp. 2015.225

Venkataraman, A., Kalk, N., Sewell, G., Ritchie, C. W., and LingfordHughes, A. (2017). Alcohol and Alzheimer's Disease-Does Alcohol Dependence Contribute to Beta-Amyloid Deposition, Neuroinflammation and Neurodegeneration in Alzheimer's Disease? Alcohol Alcohol. 52, 151-158. doi: 10.1093/alcalc/agw101

Vetreno, R. P., and Crews, F. T. (2012). Adolescent binge drinking increases expression of the danger signal receptor agonist HMGB1 and Toll-like receptors in the adult prefrontal cortex. Neuroscience 226, 475-488. doi: 10.1016/j. neuroscience.2012.08.046

Walter, T. J., and Crews, F. T. (2017). Microglial depletion alters the brain neuroimmune response to acute binge ethanol withdrawal. J. Neuroinflammation 14, 86. doi: 10.1186/s12974-017-0856-z

Ward, R. J., Colivicchi, M. A., Allen, R., Schol, F., Lallemand, F., De Witte, P., et al. (2009). Neuro-inflammation induced in the hippocampus of 'binge drinking' rats may be mediated by elevated extracellular glutamate content. J. Neurochem. 111, 1119-1128. doi: 10.1111/j.1471-4159.2009.06389.x

Weiland, N. G., Orchinik, M., and Tanapat, P. (1997). Chronic corticosterone treatment induces parallel changes in N-methyl-D-aspartate receptor subunit messenger RNA levels and antagonist binding sites in the hippocampus. Neuroscience 78, 653-662. doi: 10.1016/S0306-4522(96)00619-7

Weisskopf, M. G., O'reilly, E., Chen, H., Schwarzschild, M. A., and Ascherio, A. (2007). Plasma urate and risk of Parkinson's disease. Am. J. Epidemiol. 166, 561-567. doi: 10.1093/aje/kwm127

Weyerer, S., Schäufele, M., Wiese, B., Maier, W., Tebarth, F., van den Bussche, H., et al. (2011). Current alcohol consumption and its relationship to incident dementia: results from a 3-year follow-up study among primary care attenders aged 75 years and older. Age Ageing 40, 456-463. doi: 10.1093/ageing/ afr007

Wilhelm, C. J., Hashimoto, J. G., Roberts, M. L., Bloom, S. H., Beard, D. K., and Wiren, K. M. (2015). Females uniquely vulnerable to alcohol-induced neurotoxicity show altered glucocorticoid signaling. Brain Res. 1601, 102-116. doi: 10.1016/j.brainres.2015.01.002

World Health and Organization (2019). Global Status Report on Alcohol and Health 2018. Switzerland: World Health Organ.

Xiao, M., Zhong, H., Xia, L., Tao, Y., and Yin, H. (2017). Pathophysiology of mitochondrial lipid oxidation: role of 4-hydroxynonenal (4-HNE) and other bioactive lipids in mitochondria. Free Radic. Biol. Med. 111, 316-327. doi: 10.1016/j.freeradbiomed.2017.04.363

Yalcin, E. B., McLean, T., Tong, M., and Suzanne, M. (2017). Progressive white matter atrophy with altered lipid profiles is partially reversed by short-term abstinence in an experimental model of alcohol-related neurodegeneration. Alcohol 65, 51-62. doi: 10.1016/j.alcohol.2017.05.008

Zhang, D., Jiang, H., and Xie, J. (2014). Alcohol intake and risk of Parkinson's disease: a meta-analysis of observational studies. Mov. Disord. 29, 819-822. doi: $10.1002 / \mathrm{mds} .25863$

Zhang, Y., Chen, K., Sloan, S. A., Bennett, M. L., Scholze, A. R., O'Keeffe, S., et al. (2014). An RNA-sequencing transcriptome and splicing database of glia, neurons, and vascular cells of the cerebral cortex. J. Neurosci. 34, 11929-11947. doi: 10.1523/JNEUROSCI.1860-14.2014

Zou, J. Y., and Crews, F. T. (2014). Release of neuronal HMGB1 by ethanol through decreased HDAC activity activates brain neuroimmune signaling. PloS One 9:e87915. doi: 10.1371/journal.pone.0087915

Conflict of Interest: The authors declare that the research was conducted in the absence of any commercial or financial relationships that could be construed as a potential conflict of interest.

Copyright (c) 2020 Kamal, Tan, Ibrahim, Shaikh, Mohamed, Mohamed, Hamid, Ugusman and Kumar. This is an open-access article distributed under the terms of the Creative Commons Attribution License (CC BY). The use, distribution or reproduction in other forums is permitted, provided the original author(s) and the copyright owner(s) are credited and that the original publication in this journal is cited, in accordance with accepted academic practice. No use, distribution or reproduction is permitted which does not comply with these terms. 